\title{
Delta-Opioid Receptors Mediate Unique Plasticity onto Parvalbumin-Expressing Interneurons in Area CA2 of the Hippocampus
}

\author{
Rebecca A. Piskorowski and Vivien Chevaleyre \\ Université Paris Descartes, Sorbonne Paris Cité, IFR 95, CNRS UMR8118, Equipe ATIP, 75006 Paris, France
}

Inhibition is critical for controlling information transfer in the brain. However, the understanding of the plasticity and particular function of different interneuron subtypes is just emerging. Using acute hippocampal slices prepared from adult mice, we report that in area $\mathrm{CA} 2$ of the hippocampus, a powerful inhibitory transmission is acting as a gate to prevent CA3 inputs from driving CA2 neurons. Furthermore, this inhibition is highly plastic, and undergoes a long-term depression following high-frequency $10 \mathrm{~Hz}$ or theta-burst induction protocols. We describe a novel form of long-term depression at parvalbumin-expressing $(\mathrm{PV}+)$ interneuron synapses that is dependent on delta-opioid receptor (DOR) activation. Additionally, PV + interneuron transmission is persistently depressed by DOR activation in area CA2 but only transiently depressed in area CA1. These results provide evidence for a differential temporal modulation of PV + synapses between two adjacent cortical circuits, and highlight a new function of PV + cells in controlling information transfer.

\section{Introduction}

The primary input to the hippocampus originates from the entorhinal cortex and is conveyed through a linear set of excitatory synapses, i.e., the tri-synaptic pathway. This loop successively recruits the dentate gyrus, CA3 pyramidal cells (PCs) and CA1 PCs. The observation that ablation of CA3 inputs to CA1 PCs led to a very limited change in CA1 firing and hippocampaldependent memory formation (Brun et al., 2002, 2008; Nakashiba et al., 2008) forced the consideration of alternate pathways of information flow through the hippocampus (Piskorowski and Chevaleyre, 2012). In particular, area CA2 has been proposed to be a potentially critical component in information processing between the cortex and area CA1 (Jones and McHugh, 2011). It has been shown that CA2 pyramidal neurons are efficiently excited by inputs from the entorhinal cortex (Bartesaghi and Gessi, 2004; Chevaleyre and Siegelbaum, 2010), and furthermore, that CA2 pyramidal neurons provide a strong excitatory drive to CA1 (Chevaleyre and Siegelbaum, 2010). Given the potentially significant role of CA2, it is perplexing that there is no

Received Feb. 12, 2013; revised Aug. 5, 2013; accepted Aug. 6, 2013.

Author contributions: R.A.P. and V.C. designed research; R.A.P. and V.C. performed research; R.A.P. and V.C. analyzed data; R.A.P. and V.C. wrote the paper.

This work was supported by the ATIP/Avenir and Agence National de Recherche (ANR-12-BSV4-0021-01) programs, and the Penn Vector Core in the School of Medicine Gene Therapy Program at the University of Pennsylvania provided adeno-associated viruses. We thank Dominique Massotte and Bridget Kieffer for their helpful discussion and for providing the delta opioid receptor KO mice. We thank Jonathon Bradley for his assistance with the B6; 129P2-Pvalbtm1(cre)Arbr/J mouse line as well as providing necessary materials for stereotaxic injection. We also thank Kaoutsar Nasrallah for her aid with experiments.

The authors declare no competing financial interests.

Correspondence should be addressed to Dr Vivien Chevaleyre, Université Paris Descartes, Sorbonne Paris Cité, IFR 95, CNRS UMR8118, Equipe ATIP, 45 rue des Saints-Pères, 75006 Paris, France. E-mail: vivien.chevaleyre@parisdescartes.fr.

DOI:10.1523/JNEUROSCI.0649-13.2013

Copyright $\odot 2013$ the authors $\quad 0270-6474 / 13 / 3314567-12 \$ 15.00 / 0$ activity-dependent postsynaptic plasticity at the CA3-CA2 synapse due to the unique expression of calcium-buffering proteins and the G-protein signaling protein, RGS-14 (Zhao et al., 2007; Simons et al., 2009; Lee et al., 2010).

For proper hippocampal function, the balance between excitation and inhibition is critical. Inhibitory transmission can have a profound impact on the strength and plasticity of excitatory synapses. For instance, the feedforward inhibition recruited by the hippocampal Schaffer collateral (SC) inputs decreases EPSPs (excitatory postsynaptic potential) between CA3 and CA1 pyramidal neurons (Ormond and Woodin, 2009). In addition, it has long been known that GABAergic transmission negatively controls the induction of long-term potentiation (LTP) at the SC to CA1 synapse (Wigström and Gustafsson, 1985). A prototypical example of inhibition limiting excitation can be found in area CA2 of the hippocampus. Area CA2 contains a very high density of interneurons (Benes et al., 1998; Andrioli et al., 2007) that act to completely impede CA3 from driving CA2 neurons (Chevaleyre and Siegelbaum, 2010). Therefore, it seems that SC inputs do not provide a strong and plastic drive to CA2. However, when inhibition is pharmacologically blocked, the SC EPSPs are much larger and CA3 can drive action potential firing in CA2 (Chevaleyre and Siegelbaum, 2010). This indicates that a modulation of inhibitory transmission in CA2, particularly a reduction, will have a profound impact on the strength of excitatory transmission between CA3 and CA2.

In this study, we present a novel form of long-term depression at inhibitory synapses (I-LTD) in CA2 that is mediated by deltaopioid receptor (DOR) activation. Using optogenetic methods, we show that inhibitory transmission from parvalbuminexpressing $(\mathrm{PV}+)$ interneurons is larger in CA2 than in CA1. Additionally, we find that the DOR-mediated I-LTD likely involves this population of interneurons. In contrast, $\mathrm{PV}+$ trans- 
mission in CA1 does not express LTD, but undergoes a transient depression upon DOR activation. These results suggest a unique modulation and function of PV + cells in area CA2.

\section{Materials and Methods}

Slice preparation. Transverse hippocampal slices were prepared from 6- to 10-week-old C57BL6 male mice. Animals were anesthetized with isofluorane and killed in accordance with institutional regulations. Hippocampi were removed and placed upright into an agar mold. Transverse slices $(400 \mu \mathrm{M})$ were cut on a vibratome (Leica VT1200S) in ice-cold extracellular solution containing the following (in $\mathrm{mm}$ ): $10 \mathrm{NaCl}, 195$ sucrose, $2.5 \mathrm{KCl}, 15$ glucose, $26 \mathrm{NaHCO}_{3}, 1.25 \mathrm{NaH}_{2} \mathrm{PO}_{4}, 1 \mathrm{CaCl}_{2}$, and 2 $\mathrm{MgCl}_{2}$. The slices were then transferred to $30^{\circ} \mathrm{C}$ ACSF (in mM: $125 \mathrm{NaCl}$, $2.5 \mathrm{KCl}, 10$ glucose, $26 \mathrm{NaHCO}_{3}, 1.25 \mathrm{NaH}_{2} \mathrm{PO}_{4}, 2 \mathrm{Na}$ pyruvate, $2 \mathrm{CaCl}_{2}$, and $1 \mathrm{MgCl}_{2}$ ) for $30 \mathrm{~min}$ and then kept at room temperature for at least $1.5 \mathrm{~h}$ before recording. Cutting and recording solutions were both saturated with $95 \% \mathrm{O}_{2}$ and $5 \% \mathrm{CO}_{2}$, $\mathrm{pH}$ 7.4. All experiments were performed at $33^{\circ} \mathrm{C}$

Stereotaxic viral injections and immunohistochemistry. The adenoassociated virus AAV2/9.EF1a.DIO.hChR2(H134R)-EYFP.WPRE.hGH was purchased from the Penn vector core at the University of Pennsylvania. One milliliter of virus was injected unilaterally into the right dorsal hippocampus of 4-week-old male B6;129P2-Pvalbtm1(cre)Arbr/J mice that express the cre recombinase in the Pvalb locus. The locus of the injection site was as follows: anterior-posterior relative to bregma: -2.3 $\mathrm{mm}$; medial-lateral relative to midline: $2.5 \mathrm{~mm}$; dorsal-ventral relative to surface of the brain: $-1.75 \mathrm{~mm}$. The resulting infected area spanned at least $2 \mathrm{~mm}$ along the longitudinal axis of the injected hippocampus. We examined the fraction of $\mathrm{PV}+$ cells that also expressed ChR2 by performing immunohistochemistry and found that all CA subfields contained a similar fraction of infected PV + cells (see Results). To minimize potential differences in the level of ChR2 expression due to multiple infections close to the injection site, CA1 and CA2 PCs were recorded at similar distances from the injection site along the longitudinal axis. Slices for electrophysiology were prepared from injected animals 4-6 weeks after injection. For histology experiments, 8-week-old male mice were transcardially perfused, the brains dissected, postfixed, and $50 \mu \mathrm{m}$ floating coronal sections were prepared as previously described (Piskorowski et al., 2011). Eight serial sections were selected spanning bregma -1.8 to -2.1. A rabbit anti-parvalbumin antibody (Swant) was used at a dilution of 1:2000, the mouse monoclonal anti-RGS14 antibody (Neuromab) was used at dilution of 1:300, and a goat anti-rabbit AlexaFluor-549 and goat anti-mouse AlexaFluor-647-conjugated secondary antibodies (Life Technologies) were used at 1:400 dilution. Images were collected with a Zeiss 710 laser-scanning confocal microscope. Z-series images consisting of two channels were collected every $7 \mu \mathrm{m}$ over a total distance of $35 \mu \mathrm{m}$ per slice. RGS14 staining was used to define areas CA2, CA1, and CA3. These regions of interest were created with the RGS14 channel and applied to the channel with PV staining for counting of interneuron densities. All image analysis was performed with ImageJ.

Electrophysiological recordings and analysis. Whole-cell recordings were obtained from pyramidal neurons in current-clamp mode held at $-73 \mathrm{mV}$ with a patch pipette (3-4 M $\Omega$ ) containing the following (in mM): $135 \mathrm{~K}$ methyl sulfate, $5 \mathrm{KCl}, 0.1$ EGTA-Na, 10 HEPES, $2 \mathrm{NaCl}, 5$ ATP, 0.4 GTP, and 10 phosphocreatine (pH 7.2; 280-290 mOsm). Whole-cell recordings of IPSCs (inhibitory post-synaptic current) were performed in voltage-clamp mode with the cells held at $0 \mathrm{mV}$ and in the presence of $10 \mu \mathrm{M}$ NBQX and $50 \mu \mathrm{M}$ D-APV with an internal solution containing $\mathrm{Cs}$ methyl sulfate in place of $\mathrm{K}$ methyl sulfate. Membrane potentials were corrected for liquid junction potential, which was measured to be $\sim 3 \mathrm{mV}$. Series resistance (typically 11-18 M $\Omega$ ) was monitored throughout each experiment; cells with $>15 \%$ change in series resistance were excluded from analysis. Synaptic potentials were evoked by monopolar stimulation with a patch pipette filled with ACSF and positioned in the middle of CA1 SR (stratum radiatum). When axons of CA2 pyramidal neurons were directly recruited by the stimulation pipette, as observed with a back-propagating AP in the recorded CA2 neuron, the stimulating pipette was moved until the direct activation of the axon disappeared. Photostimulation of $0.1 \mathrm{~ms}$ pulses of blue light was provided with a $473 \mathrm{~nm}$ light-emitting diode (controlled by a CoolLED model PE-100) driven by a transistor-transistor logic pulse. The light intensity used during the plasticity experiments was between 10-20 $\mathrm{W} / \mathrm{mm}^{2}$. This was measured at the appropriate focal length under the objective with a Fieldmate model light meter (Coherent) at different power intensities.

CA2 pyramidal neurons were identified by their location, dendritic morphology, and electrophysiological properties (input resistance, membrane capacitance, resting membrane potential, sag amplitude, action potential amplitude, and duration) as previously described (Chevaleyre and Siegelbaum, 2010). For all experiments monitoring IPSCs, the properties of the cell were recorded immediately after break-in before the $\mathrm{Cs}^{+}$ion sufficiently diffused into the cell. In a fraction of experiments, $0.2 \%$ biocytin was added to the intracellular solution and labeled with AlexaFluor-488-conjugated streptavidin to confirm post hoc that the recorded cell was a CA2 pyramidal neuron by the colocalization with RGS14 as well as the shape of the dendritic arbor (Fig. 1A).

LTD was induced by tetanic stimulation (HFS: 100 pulses at $100 \mathrm{~Hz}$ repeated twice at $20 \mathrm{~s} ; 10 \mathrm{~Hz}$ and $1 \mathrm{~Hz}: 100$ pulses at $10 \mathrm{~Hz}$ or $1 \mathrm{~Hz}$ repeated twice at $20 \mathrm{~s}$; theta-burst protocol: 5 bursts of 5 pulses, 100 $\mathrm{Hz}$ within burst, $200 \mathrm{~ms}$ interburst interval, repeated four times) after at least $15 \mathrm{~min}$ of stable baseline recording. The magnitude of LTD was estimated by comparing averaged responses $30-40 \mathrm{~min}$ after the induction protocol with baseline-averaged responses $0-10 \mathrm{~min}$ before the induction protocol. All data were acquired with Axograph X software (AxoGraph Scientific) and analyzed with Origin Pro (OriginLab), and Igor Pro (Wavemetrix). Statistical comparisons were performed using Student's $t$ test. Results are reported as mean \pm SEM. All drugs were bath-applied following dilution into the external solution from concentrated stock solutions.

\section{Results}

\section{Inhibition tightly controls EPSP amplitude at CA3-CA2 synapses}

There exists a large difference between CA1 and CA2 pyramidal cells in the level of excitatory drive from SC axons of CA3 (Chevaleyre and Siegelbaum, 2010). We postulated that this dramatic disparity might be due to a strong inhibitory component at this synapse. To investigate the impact of inhibition at this synapse, we stimulated SC fibers with a glass stimulating pipette in SR of CA1 and measured the amplitude of the resulting postsynaptic potentials (PSPs) in CA1 and CA2 in the presence and absence of $\mathrm{GABA}_{\mathrm{A}}$ and $\mathrm{GABA}_{\mathrm{B}}$ receptor blockers $(1 \mu \mathrm{M}$ SR95531 and $2 \mu \mathrm{M}$ CGP55845). The PSPs that we measured in the absence of GABA receptor blockers are a mix of IPSPs and EPSPs; hence, following GABA receptor block, the responses are EPSPs. In CA1 pyramidal neurons, the PSP resulting from SC stimulation was robust with a very reproducible shape. After blocking inhibition with GABA receptor antagonists we observed a consistent ( $\sim 2-3$-fold) enhancement of the PSP amplitude resulting from SC stimulation at all stimulus intensities (for instance $2.05 \pm 0.48$-fold at $8 \mathrm{~V}$, $2.72 \pm 0.70$-fold at $12 \mathrm{~V}, 1.99 \pm 0.29$-fold at $14 \mathrm{~V}$; Fig. $1 B-D ; n=$ $5)$. In contrast, the SC-evoked PSPs in CA2 pyramidal neurons were very small in control conditions $(<3 \mathrm{mV})$, with the rising depolarizing segment of the waveform truncated by a large hyperpolarization. Following the addition of GABA blockers, we saw a dramatic effect on the PSP amplitude and waveform shape. The PSP increased by $~ 5-6$-fold and the latent hyperpolarization was no longer detectable $(5.85 \pm 0.96$-fold at $8 \mathrm{~V}, 5.81 \pm$ 1.06 -fold at $12 \mathrm{~V}, 4.8 \pm 0.46$-fold at $14 \mathrm{~V}$; Fig. $1 \mathrm{E}-\mathrm{G} ; n=7$ ). This initial finding reveals that the inhibition in area CA2 strongly limits the ability of SC fibers to excite CA2 pyramidal neurons.

These results demonstrate that inhibition tightly controls PSP amplitude and prevents CA3 inputs from exciting CA2 pyramidal neurons. Furthermore, in the absence of inhibition, CA3 pro- 

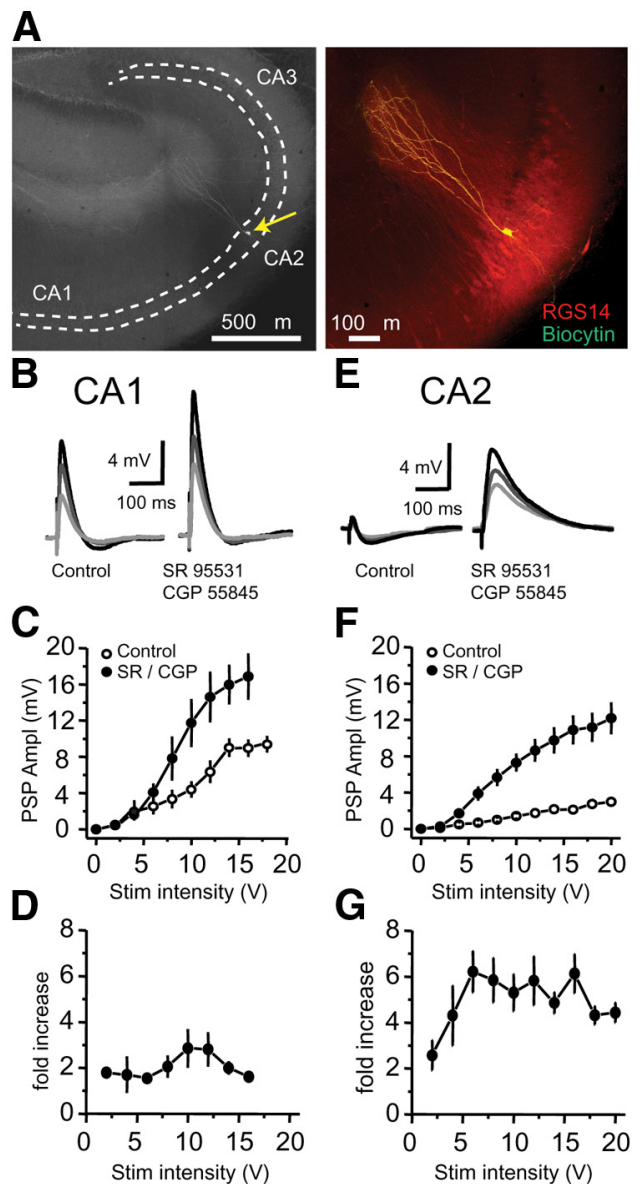
E

$\mathrm{CA} 2$
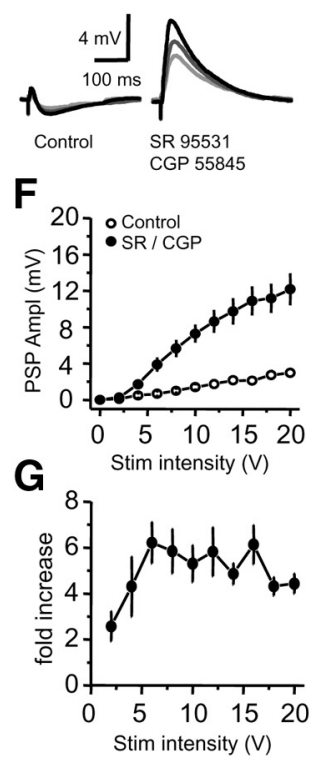

Figure 1. Stimulation of the $S C$ pathway evokes a very strong inhibition in area CA2.A, Left, Low-magnification image of the hippocampus with a CA2 pyramidal neuron (arrow) filled with labeled biocytin. Right, Higher-magnification image of the same filled neuron (green) with superimposed immunolabeling for RGS14 (red), a protein strongly enriched in CA2 pyramidal neurons. $\boldsymbol{B}$, Example of CA1 pyramidal cell PSP traces in response to a 6,10 , and $14 \mathrm{~V}$ Schaffer collateral stimulus before (control) and after blocking GABA transmission with $1 \mu \mathrm{m}$ SR95531 and $2 \mu \mathrm{m}$ CGP55845. C, The input-output curves of the CA1 pyramidal cell PSP amplitude peak with increasing stimulus intensity with (filled circles) and without (open circles) GABA transmission blocked with SR95531 and CGP55845 $(n=5)$. PSP amplitude could not be monitored for the highest stimulation intensities because most cells were firing action potentials. $\boldsymbol{D}$, The foldincreases in PSP magnitude following GABA transmission block for CA1. $E$, CA2 pyramidal cell PSP traces in response to 6,10 , and $14 \mathrm{~V}$ Schaffer collateral stimulus before and after block of GABA transmission. $\boldsymbol{F}$, Input-output curves of CA2 pyramidal cell PSP magnitude with (filled circles) and without (open circles) GABA transmission blocked with SR95531 and CGP55845 $(n=7)$. G, The fold-increase in PSP magnitude following GABA transmission block. Error bars show SEM.

vides a strong excitatory drive for CA2. Given the fact that the excitatory SC-CA2 synapses do not express LTP (Zhao et al., 2007; Chevaleyre and Siegelbaum, 2010), these results present the possibility that inhibition in CA2 may be critical in regulating transmission between CA3 and CA2.

\section{Activity-dependent LTD at inhibitory synapses in CA2}

We hypothesized that although CA2 pyramidal neurons are unable to express postsynaptic plasticity at SC synapses, perhaps the strong inhibition that is acting to prevent CA3 from exciting CA2 is plastic in an activity-dependent way. To test this, we directly measured IPSCs in CA2 by performing whole-cell voltage-clamp recordings of CA2 pyramidal neurons with a cesium intracellular solution. We blocked excitatory transmission by recording in the continuous presence of NBQX $(10 \mu \mathrm{M})$ and D-APV $(50 \mu \mathrm{M})$. We stimulated SC fibers with a glass pipette in the SR of CA1 with the
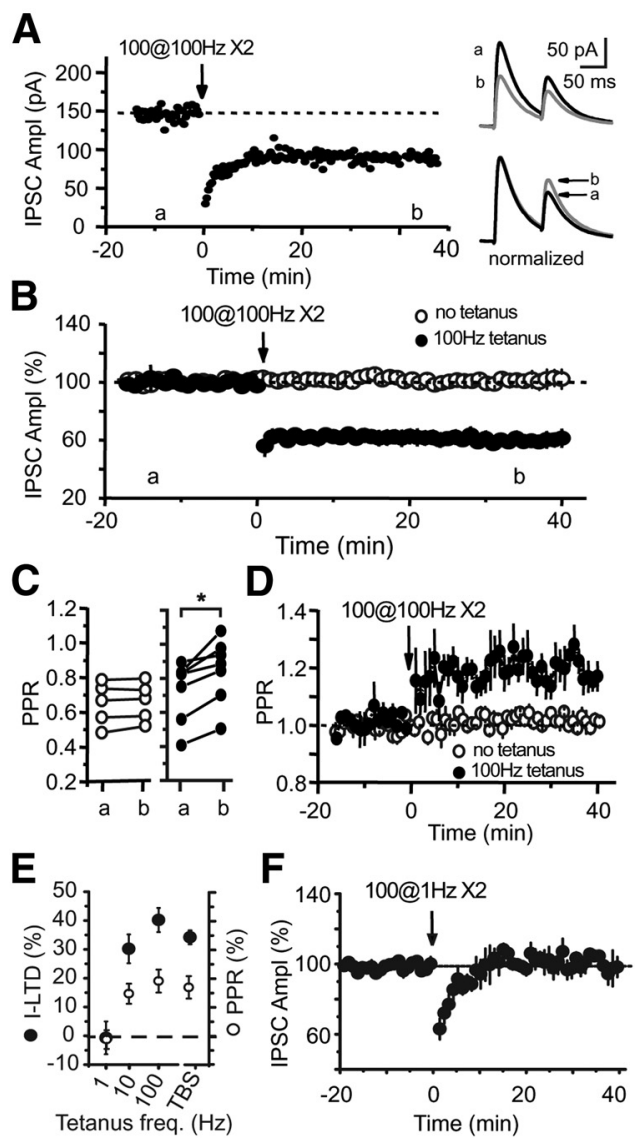

Figure 2. There is an activity-dependent LTD of inhibition in area CA2. $\boldsymbol{A}$, The amplitude of a CA2 pyramidal neuron IPSCs in a representative experiment illustrating how a HFS delivered in SR results in I-LTD. Right, IPSC traces corresponding to time points before (a) and after (b) the HFS tetanus. If the traces are normalized (bottom traces) to the peak of the first IPSC, the increase in the PPR with I-LTD is apparent. $\boldsymbol{B}$, Summary data of HFS-evoked I-LTD (filled circles, $n=9$; control recordings with no tetanus, open circles, $n=5$ ) in (A2 resulting in a reduction of IPSC magnitude of $59.8 \pm 4.2 \%$. C, The change in PPR at the time points, $a$ and b, in $\boldsymbol{B}$ for control (open circles) and recordings with HFS (filled circles). A consistent increase is observed in the PPR following HFS induced I-LTD in CA2 PCs. ${ }^{*} p<0.05$. D, Time course of the normalized PPR magnitude ( $n=7$ tetanized, $n=5$ control) showing the increase in PPR after induction of I-LTD. E, CA2 I-LTD can be induced by several different induction protocols. Plot of I-LTD (filled circles) and PPR (open circles) percentages observed following two sets of 100 pulses at 1, 10, and $100 \mathrm{~Hz}$, and TBS. F, № I-LTD is observed following a $1 \mathrm{~Hz}$ stimulus protocol $(n=4)$. Error bars show SEM.

following high-frequency stimulation (HFS): two trains of 100 stimuli at $100 \mathrm{~Hz}$ delivered $20 \mathrm{~s}$ apart. This stimulus is traditionally used to evoke LTP at excitatory SC-CA1 synapses and LTD at interneuron-CA1 synapses, but fails to evoke any lasting plasticity at excitatory SC-CA2 synapses (Zhao et al., 2007; Simons et al., 2009; Lee et al., 2010).

We found that a HFS triggered a robust LTD of the CA2 pyramidal neuron IPSC amplitude (Fig. $2 A$ ). This I-LTD was on average $59.8 \pm 4.2 \%$ of baseline (Fig. $2 B ; n=9, p<0.00001$ ), was very stable and lasted at least $80 \mathrm{~min}$ after induction. We examined the ratios of peak amplitudes in paired pulses $100 \mathrm{~ms}$ apart before and after I-LTD induction, and found that I-LTD was accompanied by a significant increase in the paired-pulse ratio (PPR) after tetanus (Fig. 2C,D; $19 \pm 4 \%, n=8, p=0.013$ ), suggesting that the I-LTD is potentially a result of a decrease in presynaptic GABA release. This depression was not due to a run down in inhibitory transmission as no change in IPSC amplitude was observed in untetanized slices (Fig. 2B; $99.9 \pm 3.3 \%, n=5$, 
$p=0.87$ with baseline and $p=0.00003$ with tetanized slices). Similarly, the PPR was also not affected over time in untetanized slices (Fig. 2C,D; $102.5 \pm 1.3 \%, p=0.79$ with baseline and 0.011 with tetanized slices).

HFS is commonly used to evoke plasticity in slices but such activity may occur only during pathological conditions in the hippocampus in vivo, and may not accurately reflect physiological activity. Therefore, we tested whether other frequencies of stimulation could also evoke I-LTD. We found that a $10 \mathrm{~Hz}$ stimulation, as well as a theta burst stimulation (TBS) were also very efficient to trigger I-LTD in CA2 (Fig. 2E; with $10 \mathrm{~Hz}$ : $69.8 \pm$ 5.0\%, $n=6$; with TBS: $65.9 \pm 2.4 \%, n=4)$. In addition, both 10 $\mathrm{Hz}$ and TBS increased the PPR (Fig. 2E; $114.6 \pm 3.5 \%$ with $10 \mathrm{~Hz}$ and $116.8 \pm 3.9 \%$ with TBS). However, a $1 \mathrm{~Hz}$ stimulation protocol did not trigger any lasting plasticity in IPSC amplitude or PPR (Fig. $2 E, F ; 100.7 \pm 5.7 \%$ for IPSC and $98.8 \pm 3.3 \%$ for PPR, $n=4)$. Therefore, I-LTD in CA2 can be evoked over a wide range of stimulation frequencies and with a protocol mimicking activity observed in vivo during important behavioral processes such as sleep and learning.

\section{I-LTD induction at inhibitory synapses in CA2 is mediated by DORs}

The I-LTD that we observed at inhibitory synapses in CA2 is similar to the endocannabinoid I-LTD that has been described at inhibitory-CA1 synapses (Chevaleyre and Castillo, 2003). Because of the proximity between CA1 and CA2, we hypothesized that a potential mechanism for the reduction in presynaptic GABA release responsible for the I-LTD in CA2 could be retrograde endocannabinoid signaling and the activation of presynaptic CB1 receptors. To test this prediction, we applied AM 251 (4 $\mu \mathrm{M}) 15$ min before the tetanus to block CB1 receptors. As reported previously, I-LTD in CA1 was completely blocked by the CB1 receptor antagonist (Fig. 3A; $96.3 \pm 2.6 \%, n=5$ ). To our surprise, the I-LTD recorded in CA2 was unchanged, suggesting that the cannabinoid pathway underlying I-LTD at inhibitoryCA1 synapses is not involved in the plasticity we observed in CA2 (Fig. $3 B ; 70.0 \pm 4.0 \%, n=6, p=0.14$ with LTD magnitude in absence of AM 251).

It has been reported that area CA2 is strongly labeled with radiolabeled ligands for $\mu$-opioid receptors (MORs) and DORs (Duka et al., 1981; Crain et al., 1986). Consistent with this finding, prominent enkephalin staining has been reported in fibers in area CA2 (Sar et al., 1978). Furthermore, MORs and DORs have been implicated in LTP at the lateral perforant path-dentate gyrus granule cell synapse, possibly by transiently decreasing GABA transmission during HFS (Bramham and Sarvey, 1996). Additionally, MORs have been shown to reduce GABA release in CA1 basket cell-pyramidal cell synapses (Glickfeld et al., 2008). Therefore, we surmised that opioid receptors are potentially playing a role in the I-LTD we observe in CA2. To test this hypothesis, we first examined the effects of selective MOR and DOR antagonists. We found that in presence of $1 \mu \mathrm{M}$ of D-Phe-CysTyr-D-Trp-Orn-Thr-Pen-Thr-NH2 (CTOP), a selective MOR antagonist, I-LTD could be induced (Fig. 3C; $69.3 \pm 3.5 \%, n=$ 5 ), and its magnitude was not significantly different from the I-LTD observed in control conditions $(p=0.16)$. To verify that CTOP was efficiently blocking MORs, we tested its ability to counteract the action of the MOR agonist DAMGO. We found that CTOP completely blocked the well described effect of DAMGO on excitability in CA1 (Dunwiddie and Su, 1988; increase in population spike: $435.2 \pm 202.8 \%$ with DAMGO, $3.3 \pm$ $2.6 \%$ with DAMGO and CTOP, $n=5$, data not shown). We then
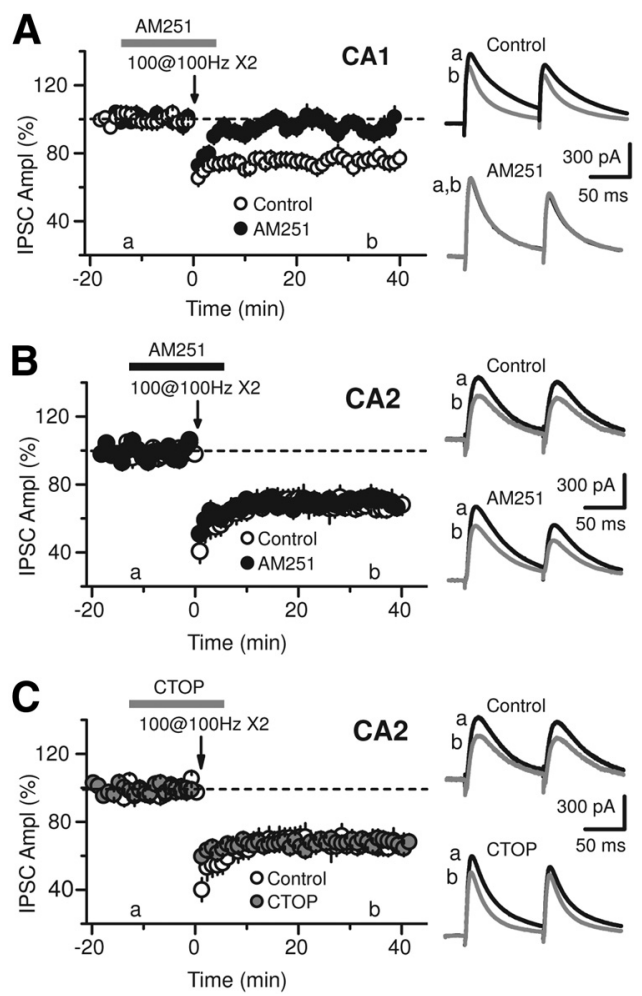

Figure 3. I-LTD in $C A 2$ is independent of $C B 1$ cannabinoid receptors and $\mu$-opioid receptors. $A$, HFS evokes I-LTD at inhibitory synapses onto CA1 pyramidal neurons (open circles, $n=5$ ). Application of $4 \mu \mathrm{M}$ of the endocannabinoid receptor antagonist AM251 $15 \mathrm{~min}$ before and during the tetanus (gray bar), is sufficient to eliminate HFS evoked I-LTD (filled circles, $n=5$ ). Right, IPSC traces corresponding to the time points before (a) and after (b) HFS performed in control conditions or with AM251 application. B, Application of AM251 (black circles, $n=6$ ) has no effect on the magnitude of I-LTD at the inhibitory-CA2 synapse (control conditions, open circles, $n=6$ ). Right, representative IPSC traces for the two experimental conditions showing before and after the induction of I-LTD. C, Likewise, application of $1 \mu \mathrm{M}$ CTOP (gray bar, gray circles, $n=5$ ) 15 min before and during HFS had no effect on I-LTD. Right, IPSC traces from two time points before and after HFS. Error bars show SEM.

tested the effect of the selective DOR competitive antagonist ICI 174864. With ICI $174864(2 \mu \mathrm{M})$ present in the bath, the tetanus induced a transient decrease in the IPSC amplitude that returned to baseline within $20 \mathrm{~min}$ (Fig. $4 A ; 97.8 \pm 3.5 \%, p=0.64, n=7$ ). However, we observed normal I-LTD after washout of the drug or in interleaved experiments (Fig. $4 A ; 65.4 \pm 3.3 \%, n=6$ ). We also tested the effect of naltrindol, another DOR antagonist. We found that I-LTD was completely blocked in presence of naltrindol (Fig. $4 A ; 106.7 \pm 4.7 \%, p=0.22$ with baseline, $p=0.00004$ with control LTD, $n=5$ ). In addition, with DORs blocked, we did not observe a change in PPR after the HFS, indicating that the potential decrease in presynaptic GABA release may be mediated by the DORs $(102 \pm 4, p=0.74, n=7$ with ICI; $104.6 \pm 2.2 \%$, $p=0.096, n=5$ with naltrindol; Fig. $4 A$ ).

Because I-LTD in area CA2 was also induced with $10 \mathrm{~Hz}$ stimulation, we verified that the I-LTD resulting from this induction protocol was also dependent on DOR activation. We found that in presence of ICI 174864, no I-LTD was evoked with $10 \mathrm{~Hz}$ stimulation (Fig. $4 B ; 100.6 \pm 1.7, n=4$ ), indicating that DOR activation is also underlying this I-LTD.

We used DOR KO mice, Oprd1 ${ }^{-1-}$ (Filliol et al., 2000), to further test the implication of DORs in I-LTD induction. We found that I-LTD evoked with $100 \mathrm{~Hz}$ stimulation was absent in DOR KO mice, but was normal in wild-type controls (Fig. 4C; $104.8 \pm 2.1 \%$ in KO, $n=7$, four mice; $74.9 \pm 3.2 \%$ in WT, $n=$ 
A

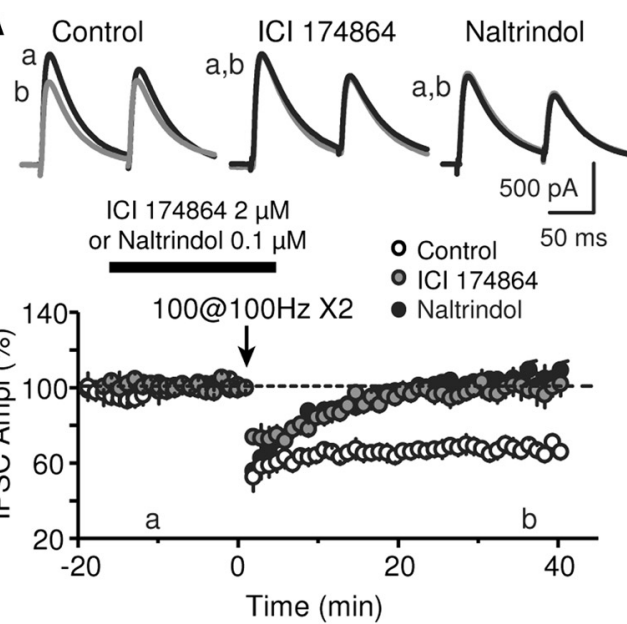

C
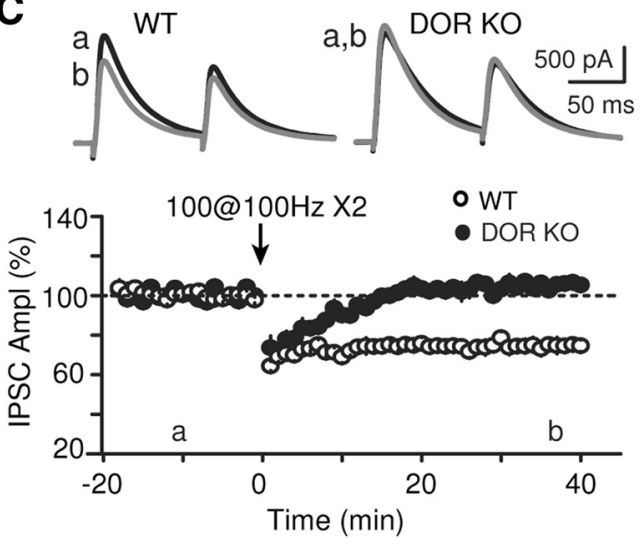

B
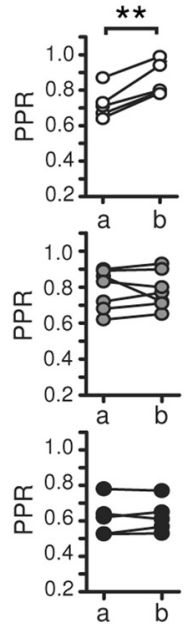

Control

ICI 174864
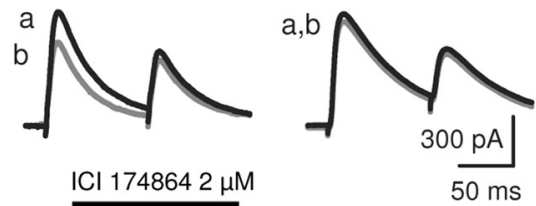

- Control
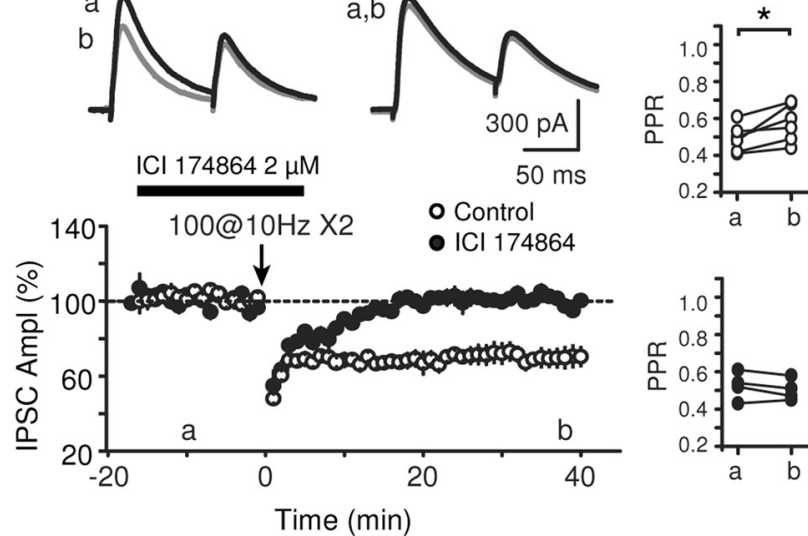

D
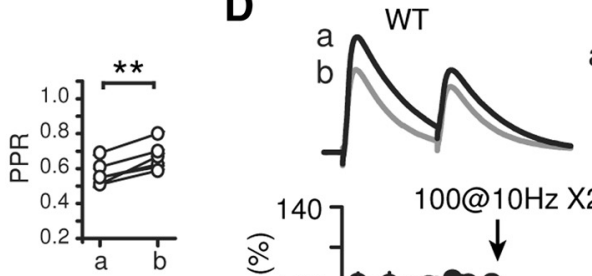

DOR KO
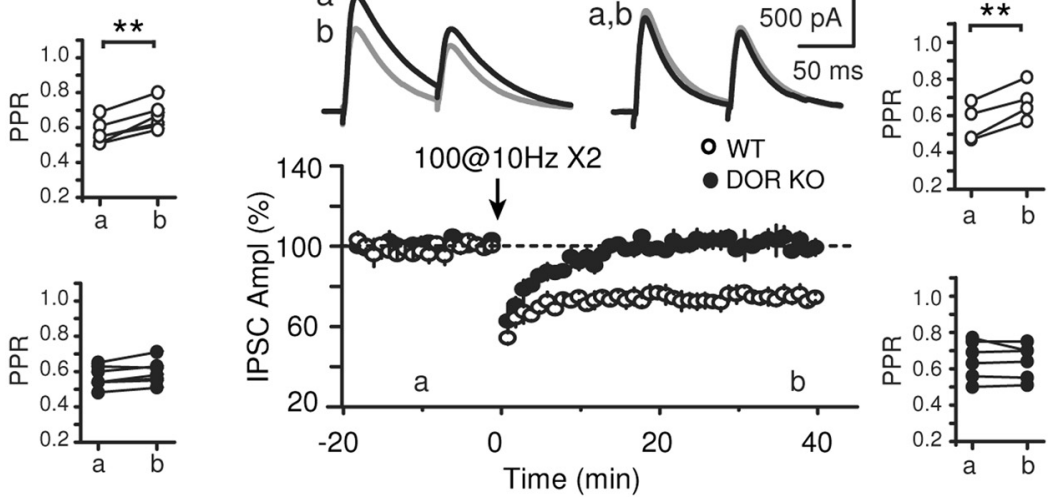

Figure 4. DORs are involved in I-LTD induction. A, HFS does not trigger I-LTD in presence of $2 \mu \mathrm{m}$ of the DOR competitive antagonist ICl 174864 (gray circles, $n=7$ ) nor in $0.1 \mu \mathrm{m}$ Naltrindol (black circles, $n=5$ ), but evokes normal LTD in interleaved control experiments (open circles, $n=6$ ). Top, IPSC traces corresponding to the time points before (a) and after (b) HFS performed in control conditions or with drug application. Right, plots of PPR from individual experiments for the three conditions at the two time points, a and b. B, Application of $2 \mu \mathrm{m} \mathrm{ICI} 174864$ during the slower frequency $10 \mathrm{~Hz}$ induction protocol also prevented I-LTD at the inhibitory-CA2 synapse (filled circles, $n=4$ ). Inset above, IPSC traces corresponding to the time points before (a) and after (b) the 10 $\mathrm{Hz} \mathrm{stimulus} \mathrm{in} \mathrm{control} \mathrm{conditions} \mathrm{or} \mathrm{during} \mathrm{ICI} 174864$ application. Right, PPR from individual experiments at two time points for both control and ICI 174864 application. C, Slices prepared from DOR K0 mice (filled circles, $n=7$ ) fail to display I-LTD in CA2 pyramidal neurons in response to HFS. Slices prepared from WT controls (open circles, $n=6$ ) display I-LTD. Inset above, IPSC traces at two time points for WT and DOR KO. Right, PPR values from individual experiments for both control and DOR KO at two time points. D, The I-LTD induced by $10 \mathrm{~Hz}$ tetanus is also absent in slices prepared from DOR KO mice (filled circles, $n=6$ ) but still present in WT controls (open circles, $n=4$ ). Inset above, traces from two time points. Right, PPR from individual experiments. ${ }^{*} p<0.05 .{ }^{* *} p<$ 0.01. Error bars show SEM in all panels.

6, four mice, $p=0.00001$ between $\mathrm{WT}$ and $\mathrm{KO})$. We also verified that $10 \mathrm{~Hz}$ I-LTD was DOR dependent, as it was also completely absent in DOR KO mice but normal in WT (Fig. $4 D$; $98.9 \pm 1.9 \%, n=6$, three mice in $\mathrm{KO} ; 75.1 \pm 2.5 \%, n=4$, two mice, $p=0.00006$ between WT and KO). Consistently, the PPR did not change after either 10 or $100 \mathrm{~Hz}$ stimulation in DOR KO mice (Fig. 4C,D; $100.9 \pm 2.1 \%$ after $10 \mathrm{~Hz}$ and $104.5 \pm 2.1 \%$ after $100 \mathrm{~Hz}$ ).

Finally, to determine whether DORs are involved in the maintenance of the I-LTD in CA2, we applied ICI $17486410 \mathrm{~min}$ after HFS and induction of I-LTD. We found that the magnitude of the depression was not reduced or reversed (data not shown; $58.2 \pm$ $1.9 \%, n=4, p=0.83$ with control LTD). This result indicates that DORs are not involved in the maintenance of LTD at inhibitory synapses in CA2. Altogether, these results show that I-LTD is blocked by two different DOR antagonists and is absent in DOR KO mice, providing strong evidence that DOR activation is required for I-LTD induction in CA2.

DOR agonist evokes and occludes I-LTD in CA2

If DORs are indeed involved in I-LTD in CA2, then it is possible to make the following predictions. A DOR agonist would evoke a similar depression of synaptic transmission, and if so, the agonist-evoked depression may occlude any LTD resulting from HFS. Furthermore, the reverse prediction can also be made: the HFS-induced depression would occlude further depression by DOR agonist.

First, we found that a transient application of the DOR agonist, DPDPE $(0.5 \mu \mathrm{M})$, persistently depressed inhibitory transmission to a similar extent as the HFS-evoked I-LTD (Fig. $5 A$; $63.8 \pm 3.4 \%, p=0.0003, n=6$ ). We believe this lasting depression is a genuine reduction of IPSC amplitude and not resulting from a lack of washout of the agonist because similar experiments performed on excitatory synapses (in presence of GABA receptor blockers) only evoked a small and reversible depression of the fEPSP (data not shown; $80.8 \pm 4.0 \%$ during DPDPE, $100.6 \pm$ $4.3 \%$ after washout, $n=6$ ). Similar to HFS, the lasting depression evoked by the agonist DPDPE resulted in an increase in the PPR, consistent with the hypothesis that the receptors involved in this I-LTD are located presynaptically (Fig. $5 C ; 120 \pm 4 \%, p=$ $0.0037, n=5$ ). We also tested SNC162, a highly selective agonist for DOR. We found that SNC162 also triggered a lasting decrease in IPSC amplitude (Fig. 5A; $75.2 \pm 5.3 \%, n=4, p=0.024$ ). However, and in accordance with its partial agonist action (Jut- 
A
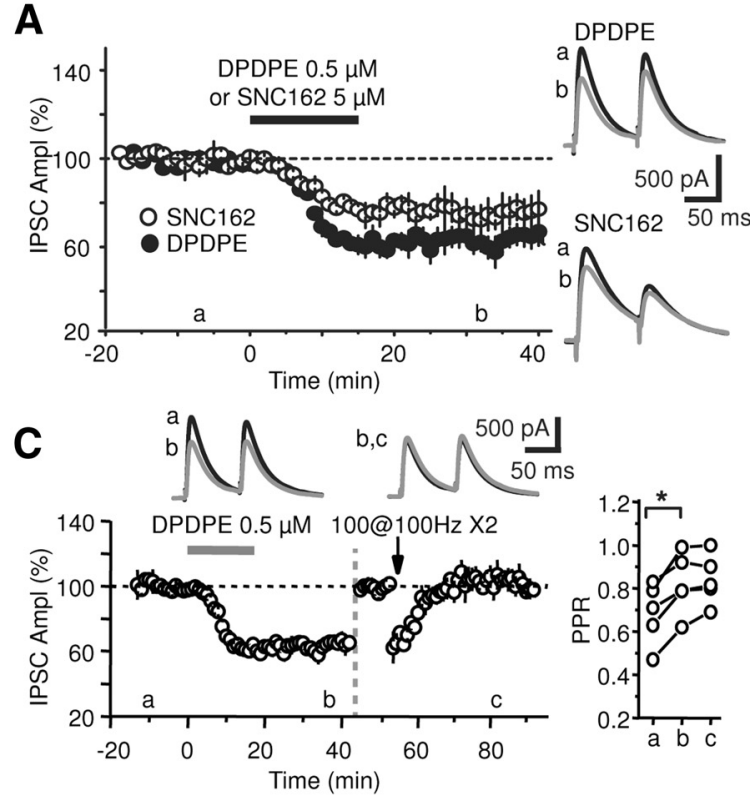

B
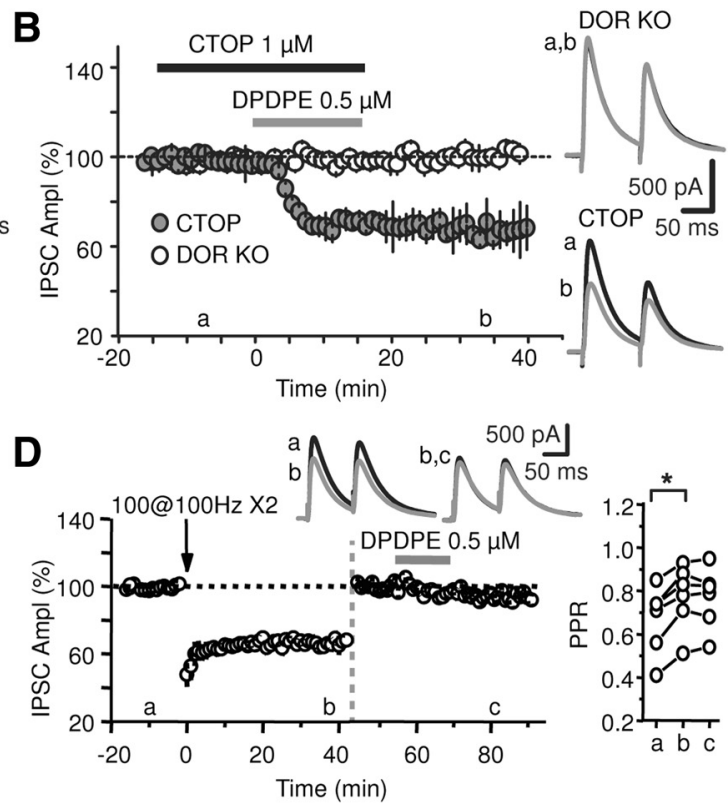

Figure 5. The DOR agonist DPDPE evokes and occludes I-LTD. A, The 15 min application of two structurally distinct DOR agonists, $0.5 \mu \mathrm{m}$ DPDPE (filled circles, $n=6$ ) or $5 \mu \mathrm{m} \mathrm{SNC162} \mathrm{(open} \mathrm{circles,}$ $n=4$ ) can evoke a lasting depression at the inhibitory-CA2 synapse. Traces at right show IPSCs at two time points, before (a) and after (b) application of DOR agonist. $\boldsymbol{B}$, Experiments showing the specific action of DOR on the induction of LTD in area CA2. Preapplication of the $\mu$-opioid receptor antagonist CTOP does not alter the depression of IPSC amplitude by DPDPE. Summary graph of CA2 pyramidal neuron IPSC amplitude measured before and after DPDPE application in the presence of CTOP (gray circles, $n=3$ ). Application of DPDPE to slices prepared from DOR KO mice (open symbols) fails to induce a lasting depression $(n=5)$. Traces to the right show example IPCSs at two time points, (a) before DPDPE applications and (b) after. C, Summary graph of CA2 neuron IPSC amplitude measured before and during the application of $0.5 \mu \mathrm{m}$ DPDPE $(n=5)$. The IPSC amplitude is renormalized to $100 \%$ at 45 min (vertical gray dashed line) showing that an additional HFS fails to induce I-LTD. Traces inset above correspond to three time points (a) before DPDPE application, (b) following depression before HFS stimulation, and (c) 25 min after HFS. Right, Plot of individual PPRs for three time points noted in the graph. D, The summary graph of CA2 IPSC amplitude showing that DPDPE application has no effect on the IPSC amplitude after HFS-induced I-LTD $(n=6)$. Amplitudes are renormalized to $100 \%$ at $45 \mathrm{~min}$ (vertical gray dashed line) to facilitate comparison. Example IPSC traces for three time points are shown in inset above. Right, Individual PPRs are plotted for three time points. ${ }^{*} p<0.05$. Error bars show SEM.

kiewicz et al., 2004), the depression was smaller than that evoked with DPDPE.

We verified that the action of DPDPE is mediated specifically by the activation of DORs, and not also by MORs. For this, we applied DPDPE in the presence of $1 \mu \mathrm{M}$ of the MOR antagonist CTOP. We found that DPDPE induced a depression of IPSCs that was not significantly different from that evoked in control conditions (Fig. $5 B ; 68.3 \pm 5.2 \%, n=3, p=0.49$ with control experiments). Furthermore, the effect of DPDPE was completely absent in DOR KO mice (Fig. 5B; $101.5 \pm 2.9 \%, n=5, p=0.0009$ with DPDPE in CTOP). This confirms that at the concentration we use, DPDPE is selectively acting on DORs. To test whether the HFS-induced depression would occlude further depression by DOR agonist, we used DPDPE rather than SNC162, because of the partial agonist action of SNC162. We found that the I-LTD evoked by DPDPE completely occluded subsequent depression by HFS (Fig. $5 C$; $99.4 \pm 2.36 \%, p=0.37, n=5$ ). In addition, DPDPE application also occluded subsequent change in PPR by HFS (Fig. $5 C ; 102 \pm 2 \%, p=0.25, n=5$ ). We then performed the complementary experiment. We found that after induction of I-LTD with HFS, DPDPE had no effect on IPSC amplitude (Fig. $5 D$; $98.7 \pm 2.0, p=0.076, n=6$ ) or on PPR (Fig. $5 D$; $99 \pm 3 \%$, $p=0.81, n=6$ ). These results demonstrate that HFS-evoked I-LTD and DOR agonist-evoked I-LTD occlude each other. This indicates that both HFS- and agonist-evoked depression share a similar DOR-mediated mechanism and potentially target the same population of interneurons.

\section{DORs act presynaptically to evoke and occlude I-LTD}

The change in PPR following DOR agonist application indicates that these receptors are acting presynaptically to depress GABA release from inhibitory terminals. To confirm this presynaptic site of action, we used a minimal stimulation intensity to activate a very small number of synapses, and quantified the proportion of failed release events before and after DOR agonist application. Because only one or a few inhibitory fibers are recruited under these conditions, it is expected that in some experiments, transmission from interneurons that do not express DORs will be unaffected by DPDPE. Indeed, we observed an effect of DPDPE on IPSP amplitude in five of eight experiments. In the experiments in which DPDPE had an effect, we observed a large decrease in the average IPSC amplitude following application of DPDPE (Fig. $6 A, B ; 44.6 \pm 4.7 \%, p=0.0008, n=5$ ). As observed with bulk stimulation, the PPR was also increased by DPDPE application (Fig. $6 C$; from $0.67 \pm 0.04$ to $0.78 \pm 0.06, p=0.03$ ). But more importantly, we observed a significant increase in the failure rate (Fig. $6 C$; from $0.33 \pm 0.02$ to $0.55 \pm 0.005, p=0.006$ ) and no significant change in synaptic potency (mean IPSC amplitude of successful events only; Fig. $6 C$; from $39.6 \pm 6.0$ to $29.9 \pm 3.2, p=0.94)$. In addition, we also observed a significant increase in the $\mathrm{CV}$ (coefficient of variation) (Fig. $6 \mathrm{C}$; from $0.96 \pm$ 0.07 to $1.32 \pm 0.08, p=0.010$ ), supporting the hypothesis that DOR activation is acting presynaptically to decrease GABA release.

To further examine the presynaptic site of action of DOR activation, we tested the effect of DPDPE on spontaneous IPSCs (sIPSCs). We found that DPDPE induced a significant decrease in sIPSC frequency. This effect was observed at the end of DPDPE application and 20-25 min after DPDPE washout (Fig. 7 A, B; $69.1 \pm 4.0 \%$ at the end of DPDPE, $p=0.00013,77.6 \pm 5.3 \%$ after washout, $p=0.0039, n=8)$. Conversely, DPDPE had no effect on sIPSC amplitude (Fig. 7B; $98.6 \pm 6.4 \%$ at the end of DPDPE, 
A

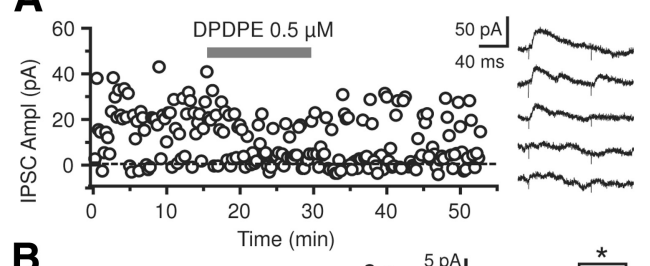

B
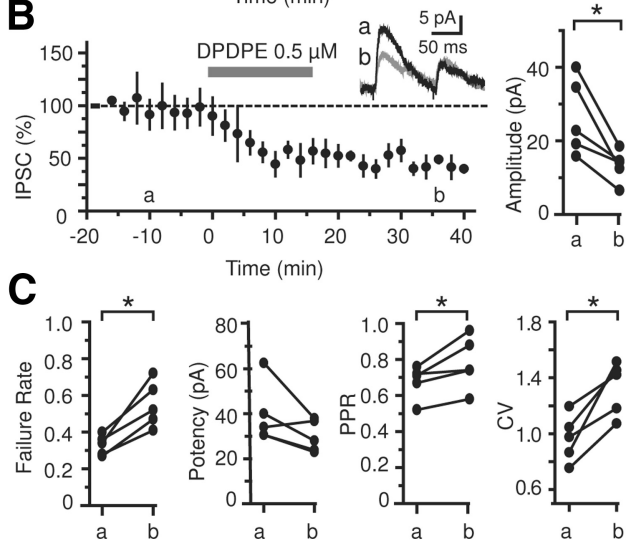

Figure 6. DORs act presynaptically to reduce GABA release. $\boldsymbol{A}$, Example data from a single experiment using minimal stimulation in SR to evoke IPSCs in CA2 pyramidal neurons. Each IPSC amplitude is plotted, and an increase in the number of failures is observed following the application of $0.5 \mu \mathrm{M}$ DPDPE. Right, Five example traces resulting from minimal stimulation (bottom two traces are considered failures). $\boldsymbol{B}$, Average IPSC amplitudes evoked by minimal stimulation $(n=5)$ showing a decrease in IPSC amplitude following application of $0.5 \mu \mathrm{M}$ DPDPE. Inset, Average of ten traces corresponding to two time points before (a) and after (b) application of DPDPE. Right, plot of the average IPSC amplitudes at time points $a$ and $b$. C, Plots of the failure rate, potency, PPR, and CV for the two time points indicated in $\boldsymbol{B}$ for all experiments. ${ }^{*} p<0.05$. Error bars show SEM.

$p=0.82,102.15 \pm 6.4 \%$ after washout, $p=0.74)$. We confirmed that this effect on SIPSC frequency was mediated by DOR activation, as it was absent in DOR KO mice (Fig. $7 B ; 101.08 \pm 3.9 \%$ at the end of DPDPE, $p=0.79$ and $104.2 \pm 1.9 \%$ after washout, $p=$ $0.12, n=4)$. Interestingly, whereas DPDPE also decreased sIPSC frequency in CA1 pyramidal neurons, this effect was transient and fully reversed following washout of DPDPE (Fig. 7B; $76.9 \pm$ $5.3 \%$ at the end of DPDPE, $p=0.023$ and $102.4 \pm 3.8 \%$ after washout, $p=0.57, n=4$ ).

To address whether DOR activation acts on GABA release downstream of $\mathrm{Ca}^{2+}$ influx, we tested the effect of DPDPE on the action-potential independent miniature IPSCs (mIPSCs). We found that DPDPE application induced a lasting decrease in CA2 mIPSC frequency without affecting mIPSC amplitude (Fig. $7 C, D$; for mIPSC frequency: $59.8 \pm 6.3 \%$ at the end of DPDPE, $p=0.003$ and $65.2 \pm 7.1 \%$ after washout, $p=0.008, n=5$; for mIPSC amplitude: $103.4 \pm 2.4 \%$ at the end of DPDPE, $p=0.22$ and $102.5 \pm 4.3 \%$ after washout, $p=0.58, n=5$ ). Consistently, the action of DPDPE on CA1 mIPSC frequency was transient (Fig. 7C,D; for mIPSC frequency: $67.8 \pm 10.5 \%$ at the end of DPDPE, $p=0.038$ and $95.1 \pm 5.9 \%$ after washout, $p=0.46, n=$ 5; for mIPSC amplitude: $100.3 \pm 5.4 \%$ at the end of DPDPE, $p=$ 0.95 and $106.7 \pm 4.9 \%$ after washout, $p=0.24, n=5$ ). From these results, we conclude that DORs are activated presynaptically on interneurons and are potentially reducing GABA release by acting on the vesicle release machinery, downstream of $\mathrm{Ca}^{2+}$ influx. Moreover, these data highlight a differential time course of action of DOR on GABA release onto CA1 and CA2 pyramidal neurons. Although the effect is transient in CA1, a lasting decrease in GABA release is observed in CA2.
A

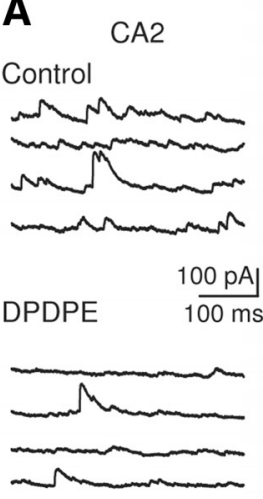

Washout

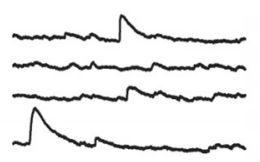

B
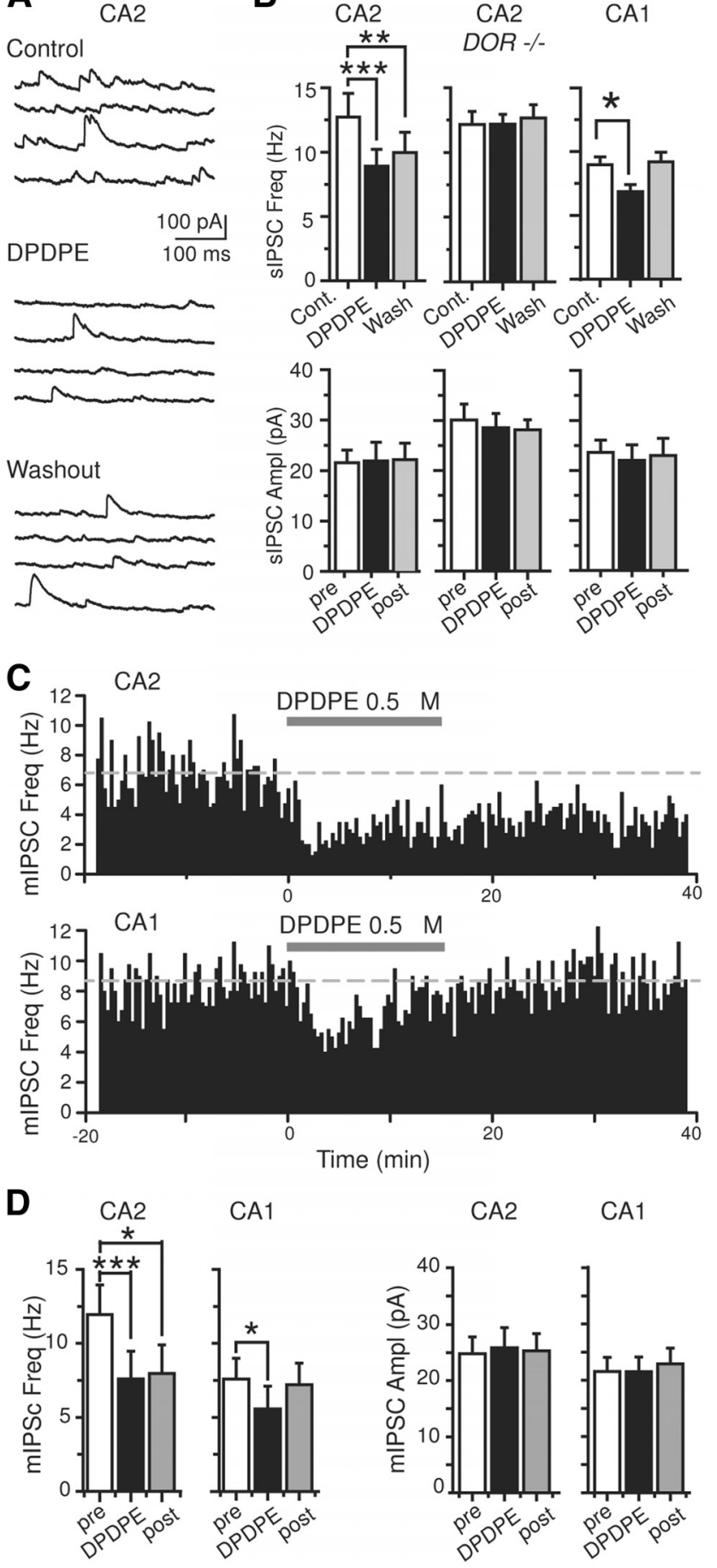

CA2

CA1

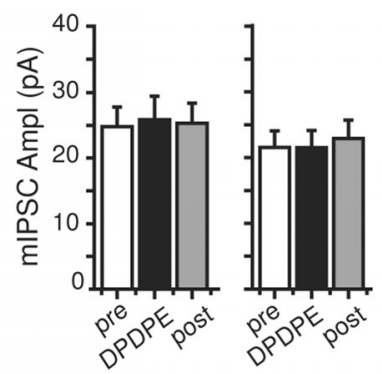

Figure 7. The time course of DOR action on GABA release differs between $C A 1$ and $C A 2$ $A$, Sample traces of spontaneous IPSCs recorded in a CA2 pyramidal neuron before, during the application, and after the washout of $0.5 \mu \mathrm{m}$ DPDPE. $B$, Histograms summarizing the effect of DPDPE on sIPSC frequency and amplitude in CA2 PCs from control and DOR KO mice and for control mice in CA1 ( $n=8$ for CA2 controls, $n=4$ for CA2 DOR KO and $n=$ 4 for (A1). C, Single example experiment showing the time course of the effect of DPDPE on miniature IPSCs frequency in CA2 and CA1 pyramidal neurons. Whereas mIPSC frequency is decreased following washout of DPDPE in CA2, a complete recovery of mIPSC frequency is observed in CA1. Dashed line marks average baseline frequency. D, Summary histograms of the effect of DPDPE on mIPSC frequency and amplitude in CA1 and CA2 pyramidal neurons ( $n=5$ for CA2 and for CA1). ${ }^{*} p<0.05,{ }^{* *} p<0.01,{ }^{* * *} p<0.001$. Error bars show SEM. 
Inhibitory transmission from $\mathrm{PV}+$ cells is decreased after I-LTD induction and by DOR activation

A functional action of DOR activation in a specific interneuron population has never been observed. It has recently been shown with a transgenic line of mice expressing GFP-tagged DORs, that the majority of DORs in the hippocampus are expressed by PV+ interneurons (Erbs et al., 2012). To isolate the inhibitory currents from $\mathrm{PV}+$ interneurons, we used a transgenic line of mice that expresses cre recombinase uniquely in PV + cells (Hippenmeyer et al., 2005). We then stereotaxically injected an adenovirus into the hippocampus to allow the expression of channelrhodopsin, $\mathrm{ChR} 2(\mathrm{H} 134 \mathrm{R})$ in the presence of cre recombinase (Sohal et al., 2009). We performed whole-cell voltage-clamp recordings of pyramidal neurons and isolated IPSCs using cesium internal solution and pharmacology as previously described. We evoked IPSCs from PV + interneurons by exciting ChR2(H134R)-EYFP with a 0.1 ms pulse of blue light delivered through a $40 \times$ immersion objective. The illumination field was centered over the pyramidal cell layer and illuminated an area of $\sim 0.2 \mathrm{~mm}^{2}$.

Using this method to isolate IPSCs from PV + cells, we first quantified the total inhibitory transmission in CA2 and CA1 PCs. We found that inhibitory transmission from $\mathrm{PV}+$ cells was $\sim 50 \%$ larger in CA2 than in CA1 (Fig. $8 A$; at 76 $\mathrm{mWatts} / \mathrm{mm}^{2}: 1.93 \pm 0.2 \mathrm{nA}, n=8$ in CA1 and $3.06 \pm 0.28 \mathrm{nA}, n=7$ in CA2, $p=0.007)$. The pulse of light likely depolarizes the soma of interneurons that are located near the recorded cell, but also axons of interneurons located outside of the illuminated area and even possibly outside of the slice. To compare the PV + inhibitory synaptic transmission onto CA1 and CA2 pyramidal neurons in a way that is independent of the somatic location of the originating interneuron, we performed the same experiment in presence of $0.2 \mu \mathrm{M}$ tetrodotoxin (TTX). With TTX, action potentials will not be evoked by light stimulation, so only the depolarization of the synaptic terminals due to the excitation of channelrhodopsin will generate IPSCs. Not surprisingly, a much stronger light intensity was needed to evoke transmission. As before, we observed a much larger transmission onto CA2 pyramidal neurons than CA1 pyramidal neurons (Fig. 8A; at $140.5 \mathrm{mWatts} /$ $\mathrm{mm}^{2}: 1.00 \pm 0.2 \mathrm{nA}, n=5 \mathrm{inCA} 1$ and $1.71 \pm 0.19 \mathrm{nA}, n=5 \mathrm{in} \mathrm{CA} 2$, $p=0.03)$.

To ensure that the larger inhibitory transmission observed in area CA2 did not result from a higher percentage of infected PV+ cells in area CA2 as compared with CA1, we performed immu0.001 . Error bars show SEM.
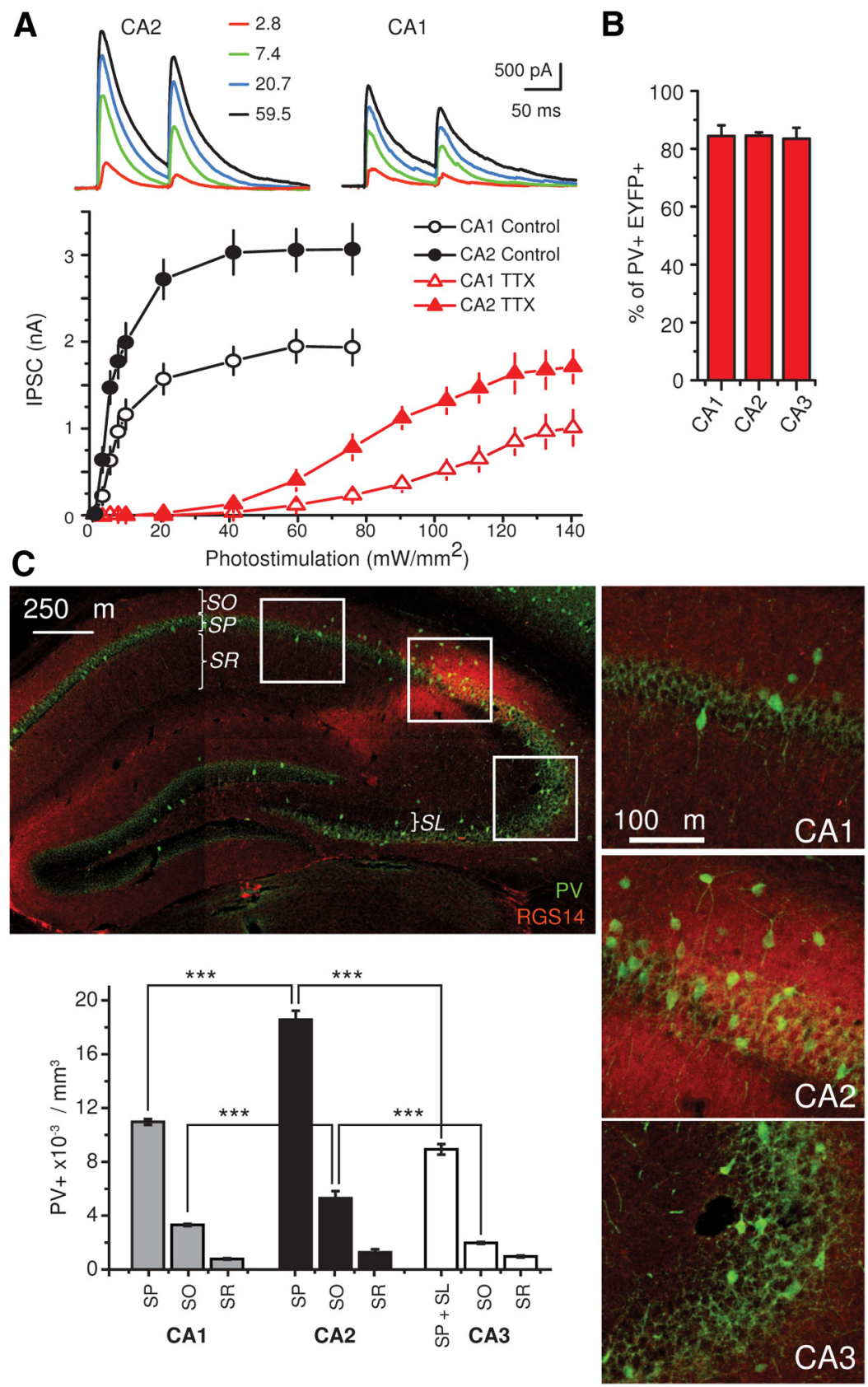

Figure 8. High level of inhibitory transmission from PV+ interneurons in CA2. ChR2(H134R) was expressed specifically in PV+ interneurons in the hippocampus. Whole-cell recordings were performed in pyramidal cells in either area CA2 or CA1 and pairs of IPSCS were invoked with two $0.1 \mathrm{~ms}$ pulses of blue light. $A$, Average peak amplitude of IPSCs over a range of light intensities $(n=$ 5) for CA1 (open symbols) and CA2 (filled symbols). Recordings were performed in the absence (circles, $n=8$ for CA2 and $n=7$ for CA1) and presence of $0.2 \mu \mathrm{M}$ TTX (triangles, $n=5$ for CA2 and CA1). In both conditions, CA2 pyramidal neurons display a larger PV + interneuron IPSC than CA1 pyramidal neurons. Sample traces resulting from four different light intensities in control conditions are shown above. $\boldsymbol{B}$, Histogram showing the percentage of PV + cells also expressing ChR2 tagged with EYFP in the three hippocampal areas after viral injection ( $n=4$ mice). C, Top left, Immunofluorescent staining of RGS14 (red), a marker for area CA2 and parvalbumin (green) in the hippocampus. Corresponding areas marked in boxes are shown in higher magnification at the right. Bottom left, Bar graph showing the density of PV + interneuron soma in the different strata of CA1, CA2 and CA3 in dorsal hippocampal sections ( $n=4$ mice). SP, Stratum pyramidale; $S 0$, stratum oriens; $S R$, stratum radiatum; $S L$, stratum lucidum. ${ }^{*} p<$

nohistochemistry to quantify the fraction of PV + cells infected by the virus. We performed a stain for PV and compared the number of labeled PV + cells to the number of cells expressing EYFP-tagged ChR2. We did not detect any difference in the proportion of PV + infected cells between CA3, CA2, and CA1 (Fig. $8 B ; 83.5 \pm 3.8 \%$ in $\mathrm{CA} 3,84.6 \pm 1.2 \%$ in CA2, $84.4 \pm 3.7 \%$ in 

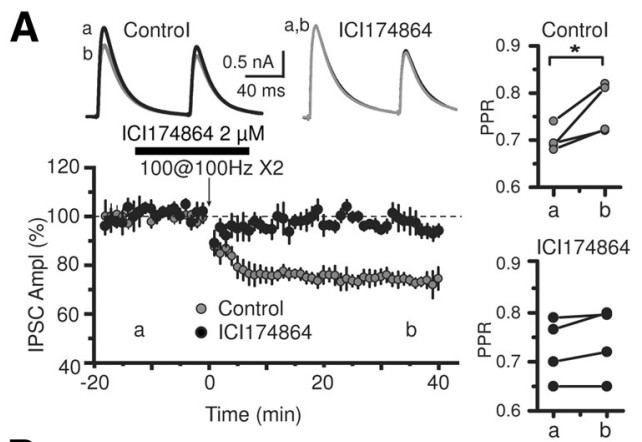

B
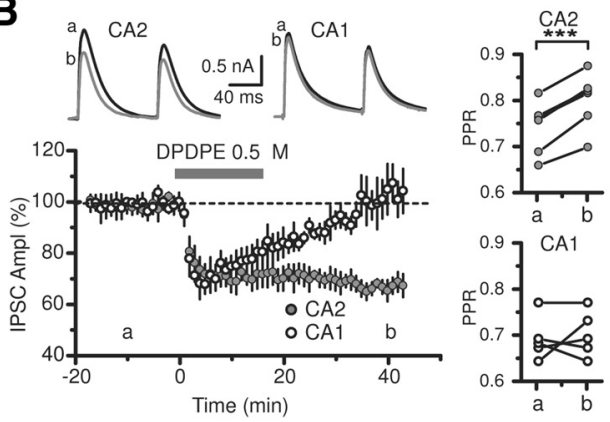

Figure 9. DOR-mediated plasticity at PV + interneurons reveals differences between CA1 and CA2.A, Electrical stimulation in SR results in I-LTD in area $C A 2$ as measured by light-evoked IPSCs from PV + interneurons (gray circles, $n=4$ ). This I-LTD is not observed with the application of $2 \mu \mathrm{M} \mathrm{ICl} 174864$ (black circles), indicating the necessity of DOR activation. Top, Example traces from two time points (a) and (b) in control conditions and with ICI 174864. Right, Plots of PPR at two time points in control and with ICI 174864. B, Plot of light-evoked IPSCs from CA1 (open circles, $n=5$ ) or CA2 (filled circles, $n=6$ ). Following application of the DOR agonist DPDPE, light-evoked PV + interneuron transmission undergoes a stable I-LTD in CA2, whereas only a transient depression is observed in CA1. Top, example light-evoked IPSCs at two time points for CA2 and CA1. Right, IPSC PPR values for the same two time points for CA2 and CA1. Error bars show SEM.

CA1, $n=4$ mice), indicating that the larger transmission is likely not a result of viral infection differences between the three regions.

Because the density of interneurons in humans was reported to be higher in CA2 than in CA1 (Benes, 1999; Andrioli et al., 2007), we tested in mice whether a higher density of PV+ interneurons could explain the increased inhibitory synaptic transmission in CA2. Therefore, we performed immunohistochemistry in brain slices to quantify the number of $\mathrm{PV}+$ interneurons in different regions of the hippocampus. The borders of the CA2 area were defined solely by the staining of RGS14, a protein highly enriched in CA2 (Lee et al., 2010). As shown in Figure $8 C$, we found that the density of PV + interneurons was much higher in CA2 than in CA1 or CA3 (for instance the number of PV + cells per $\mathrm{mm}^{3}$ in stratum pyramidale: $10,968 \pm 215$ in CA1, 18,569 \pm 662 in CA2, $8929 \pm 392$ in CA3, $n=4$ mice). This result is consistent with our observation of larger PV + IPSCs in area CA2. Furthermore, this result suggests that at least part of the powerful inhibitory control of CA3-CA2 excitatory transmission is the result of an increased number of PV + interneurons in CA2.

We then asked whether transmission from PV + cells is depressed during activity-dependent I-LTD. To determine this, we evoked two IPSCs with two pulses of blue light separated by 100 ms every $20 \mathrm{~s}$. We induced I-LTD with a tetanus delivered by a glass pipette-stimulating electrode in CA1 SR. We found that HFS evoked a lasting depression of $\mathrm{PV}+$ inhibitory transmission (Fig. 9A; $74.7 \pm 2.68 \%, p=0.00008, n=4$ ), which was also accompanied by an increase in the PPR (from $0.69 \pm 0.01$ to
$0.76 \pm 0.27, p=0.04)$. To verify that this depression was mediated by DORs, we performed the same experiment in the presence of the DOR competitive antagonist ICI 174864. Consistent with our previous results, we found no depression of the amplitude of the IPSCs (Fig. 9A; 96.2 $\pm 3.1 \%, p=0.21, n=4$ ) and no change in the PPR (from $0.72 \pm 0.03$ to $0.74 \pm 0.03, p=0.14$ ) when DORs were not activated.

Finally, we asked whether transmission from PV + cells could be directly altered by DOR activation. Application of DPDPE evoked a lasting depression of light-evoked IPSCs in CA2 neurons (Fig. 9B; $67.7 \pm 2.8 \%, n=6$ ). This depression was also accompanied by a lasting increase in PPR (Fig. 9B; $110.8 \pm 9.2 \%$, $p=0.0003$ ), suggesting a presynaptic action of DORs on PV + cells. Interestingly, inhibitory transmission from $\mathrm{PV}+$ cells in CA1 neurons was also decreased during DPDPE application. However, in contrast to CA2, this depression was only transient, as both IPSCs and PPR recovered their initial value $\sim 25-30 \mathrm{~min}$ after washout of the agonist (Fig. $9 B ; 97.7 \pm 2.8 \%, p=0.56$ for IPSCs, $103.0 \pm 1.8 \%$ for PPR, $p=0.08, n=5$ ). This result shows that DORs have a differential action on synaptic transmission from $\mathrm{PV}+$ interneurons in areas CA1 and CA2, and is consistent with the lack of DOR-mediated I-LTD in CA1 and with the effect of DORs on sIPSCs and mIPSCs.

These data highlight important differences in inhibitory transmission originating from $\mathrm{PV}+$ interneurons in different hippocampal areas. First, CA2 pyramidal cells receive a much stronger inhibitory connection from $\mathrm{PV}+$ interneurons as compared with CA1 pyramidal neurons, and second, transmission from PV + interneurons undergoes a lasting depression following DOR activation in CA2 but only a transient depression in CA1. This suggests that this very strong and highly plastic GABA transmission from $\mathrm{PV}+$ interneurons in CA2 may play an important role in hippocampal function.

\section{Discussion}

These results reveal a new form of plasticity at inhibitory synapses in the hippocampus and suggest a unique role of PV + interneurons in controlling the activity of CA2 neurons. First, we have shown the existence of a very strong feedforward inhibition onto CA2 pyramidal neurons recruited by SC stimulation. Second, this inhibition is highly plastic and undergoes a robust LTD. Third, this I-LTD is due to the activation of presynaptic DORs that likely act on release machinery to reduce GABA release. Fourth, our data implicates PV + interneurons as responsible for this I-LTD. Finally, we show that the PV + interneurons in CA2 display different plasticity properties than those in CA1.

\section{Unique delta-opioid-mediated synaptic plasticity}

Opioids have been known to increase the excitability of hippocampal pyramidal neurons and to facilitate induction of long-term plasticity at excitatory synapses via a disinhibition mechanism (Xie and Lewis, 1995; Bramham and Sarvey, 1996; Jin and Chavkin, 1999; Wagner et al., 2001). However, when the effect of opioid receptor agonist application was directly assessed on GABA transmission, only a reversible decrease was observed upon opioid receptor activation (Zieglgänsberger et al., 1979; Nicoll et al., 1980; Cohen et al., 1992; Glickfeld et al., 2008).

Conversely, only a few reports indicate that opioid receptors can directly mediate long-term plasticity. Application of MOR agonist can evoke a lasting potentiation of excitatory transmission in the spinal cord, but a similar role of endogenous opioids was not investigated (Zhou et al., 2010). In the periventricular nucleus, dynorphin can trigger LTD at excitatory synapses via 
kappa-opioid receptors only if CB1 receptors are blocked (Iremonger et al., 2011). In the ventral tegmental area, application of DOR agonist causes a postsynaptic increase in $\mathrm{GABA}_{\mathrm{A}}$ receptor surface expression only in slices prepared from rats that had previously been exposed to stressful stimuli (Margolis et al., 2011).

To our knowledge, there is no report of long-term plasticity mediated solely by DOR activation. We show that HFS, but also $10 \mathrm{~Hz}$ and TBS result in a lasting depression of inhibition onto CA2 PCs. This activity-dependent I-LTD was not affected by blocking MORs, but was completely prevented by two DOR antagonists and was absent in DOR KO mice. In addition, it could be mimicked by DOR agonists and completely occluded by the full-agonist action of DPDPE. Thus, our results reveal a novel function of DORs as potent mediators of LTD of inhibition onto PCs in area CA2.

Several studies have reported that CA2 is intensely stained when using radiolabeled ligands of DORs (Duka et al., 1981; Crain et al., 1986) and after immunohistochemical labeling of enkephalin (Sar et al., 1978). Importantly, a recent in-depth examination of the location of GFP-tagged DORs in interneurons in the hippocampus reveals that the majority of DORs are located at the presynaptic terminals of interneurons. (Scherrer et al., 2006; Rezail et al., 2012). These data are consistent with the changes we see in PPR, CV, failed events, and mIPSC frequency following DOR activation. Altogether, these data strongly indicate that DORs are acting presynaptically to decrease GABA release.

We observed a potent effect of DOR activation on action potential-independent mIPSCs, indicating that DORs may be acting downstream of $\mathrm{Ca}^{2+}$ influx on the release machinery. By activating the Gi/o family of G-proteins, DORs can potentially alter cAMP levels in the terminal (Quock et al., 1999). The level of cAMP and PKA activity is critical for LTD induction by cannabinoids at inhibitory synapses in CA1 (Chevaleyre et al., 2007). Additionally, the presynaptic protein RIM1a and Rab3b are critical for this plasticity (Chevaleyre et al., 2007; Tsetsenis et al., 2011). With our results, we cannot exclude an action of DORs upstream of $\mathrm{Ca}^{2+}$ influx, thus, further experiments are needed to firmly identify the pathway involved in the modulation of GABA release.

\section{DORs are expressed by PV+ interneurons, but have different} action in CA1 than CA2

Multiple studies have shown that DOR staining or GFP-tagged DORs colocalize with PV + interneurons (Commons and Milner, 1997; Svoboda et al., 1999; Stumm et al., 2004; Erbs et al., 2012; Faget et al., 2012). In agreement with these findings, we found that transmission from PV + interneurons is decreased after I-LTD induction and is directly decreased by application of DOR agonist. Therefore, we conclude that PV+ interneurons are a preferential target of the DOR-dependent LTD we observe in CA2.

Many differences in PV + interneurons have been described between CA1 and CA2. First, some PV + cells in CA2 have a unique morphology and extend their dendrites and axons into the three CA subfields (Mercer et al., 2007, 2012). Second, the density of PV + interneurons in humans is higher in CA2 than in the other hippocampal subfields (Benes et al., 1998; Andrioli et al., 2007) and CA2 PCs receive a much higher density of inhibitory synapses from PV + cells compared with CA1 or CA3 (Ribak et al., 1993). This is consistent with our finding that the density of $\mathrm{PV}+$ cells in mice is also much higher in CA2 and that transmission from $\mathrm{PV}+$ interneurons is larger in CA2 PCs than in CA1
PCs. Third, we find that the modulation of GABA release from $\mathrm{PV}+$ cells also differs between CA1 and CA2. PV transmission in CA2 expressed a DOR-dependent I-LTD and DOR agonist persistently depressed evoked IPSCs, sIPSCs, and mIPSCs. In contrast, we did not observe any DOR-mediated I-LTD in CA1 and DOR agonist only had a transient effect on mIPSCs and on evoked transmission from PV + interneurons in CA1.

Although the density of PV + interneurons is higher in CA2 compared with $\mathrm{CA} 1$, this alone cannot account for the different time course of DOR action on GABA release. Several potential mechanisms can be proposed to explain this difference. DORs may be expressed at higher densities in the presynaptic terminals or may have a more efficient coupling to downstream targets in area CA 2 compared with CA1. Alternatively, a specific target may be present or enriched uniquely in CA2 inhibitory terminals. Finally, a mandatory cofactor might be present in the extracellular space in CA2 and absent in CA1.

The origin and mechanism of enkephalin release is currently unknown. We found that 10 and $100 \mathrm{~Hz}$, but not $1 \mathrm{~Hz}$ stimulation, could evoke I-LTD. This frequency dependence is consistent with the idea that neuropeptides require higher activity for release than classical neurotransmitters (van den Pol, 2012). Thus, $1 \mathrm{~Hz}$ stimulation might not sufficiently increase $\mathrm{Ca}^{2+}$ in the terminal to trigger enkephalin release. In the hippocampus, enkephalins have been detected in the mossy fibers and the cortical inputs (Simmons and Chavkin, 1996). Neither of these inputs are activated by our stimulation in SR. Enkephalins have also been detected in interneurons that synapse onto other interneurons (Blasco-Ibáñez et al., 1998), and in particular onto PV+ interneurons (Fuentealba et al., 2008). Interestingly, enkephalins have been detected in GABA-containing terminals targeting other GABAergic terminals (Commons and Milner, 1996). This suggests a complex but interesting model where a subpopulation of interneurons would release enkephalin upon sufficient activity, thereby decreasing synaptic transmission from PV+ interneurons.

\section{Physiological and pathological relevance of DOR modulation of $\mathrm{PV}+$ transmission in the hippocampus}

The majority of studies examining the SC-CA2 have focused on the lack of LTP at this synapse (Zhao et al., 2007; Simons et al., 2009; Lee et al., 2010). The large feedforward inhibition and the lack of LTP at SC-CA2 synapses might suggest at first glance that information traveling through the trisynaptic pathway always bypasses CA2 and is not plastic. Our results show that the strength of excitatory SC inputs onto CA2 is tightly controlled by inhibitory transmission. Therefore, inhibition in CA2 might be acting as a gate to control the flow of information. We postulate that the I-LTD mediated by DORs could change the transfer of information between CA3, CA2, and CA1. Thus, our results suggest a potential mechanism for the hippocampal-dependent memory impairment in DOR KO mice (Le Merrer et al., 2013).

Although our results suggest a physiological role of an activity-dependent decrease in inhibition in CA2, it is likely that a more global and persistent reduction in inhibition might be detrimental to the hippocampus. For instance, during schizophrenia the density of PV + neurons is decreased in the hippocampus (Zhang and Reynolds, 2002) and a loss of inhibitory neurons has been reported to occur uniquely in CA2 (Benes et al., 1998). Similarly, the density of PV + interneurons is reduced in CA2 during epilepsy (Andrioli et al., 2007), and physiological recordings in the hippocampi of human epileptic patients revealed an important decrease (Wittner et al., 2009) or a complete loss of 
inhibition in CA2 PCs (Williamson and Spencer, 1994). Our results provide a potential mechanism of how a persistent decrease in inhibition results in an altered trisynaptic circuit during schizophrenia (Benes, 1999), and why CA2 may be a locus of epileptiform activity generation both in rodents (Knowles et al., 1987) and in humans (Wittner et al., 2009). Furthermore, they also provide a potential mechanism for the pro-epileptic action of DOR agonists (Jutkiewicz et al., 2005).

\section{References}

Andrioli A, Alonso-Nanclares L, Arellano JI, DeFelipe J (2007) Quantitative analysis of parvalbumin-immunoreactive cells in the human epileptic hippocampus. Neuroscience 149:131-143. CrossRef Medline

Bartesaghi R, Gessi T (2004) Parallel activation of field CA2 and dentate gyrus by synaptically elicited perforant path volleys. Hippocampus 14: 948-963. CrossRef Medline

Benes FM (1999) Evidence for altered trisynaptic circuitry in schizophrenic hippocampus. Biol Psychiatry 46:589-599. CrossRef Medline

Benes FM, Kwok EW, Vincent SL, Todtenkopf MS (1998) A reduction of nonpyramidal cells in sector CA2 of schizophrenics and manic depressives. Biol Psychiatry 44:88-97. CrossRef Medline

Blasco-Ibáñez JM, Martínez-Guijarro FJ, Freund TF (1998) Enkephalincontaining interneurons are specialized to innervate other interneurons in the hippocampal CA1 region of the rat and guinea-pig. Eur J Neurosci 10:1784-1795. CrossRef Medline

Bramham CR, Sarvey JM (1996) Endogenous activation of mu and delta-1 opioid receptors is required for long-term potentiation induction in the lateral perforant path: dependence on GABAergic inhibition. J Neurosci 16:8123-8131. Medline

Brun VH, Otnass MK, Molden S, Steffenach HA, Witter MP, Moser MB, Moser EI (2002) Place cells and place recognition maintained by direct entorhinal-hippocampal circuitry. Science 296:2243-2246. CrossRef Medline

Brun VH, Leutgeb S, Wu HQ, Schwarcz R, Witter MP, Moser EI, Moser MB (2008) Impaired spatial representation in CAl after lesion of direct input from entorhinal cortex. Neuron 57:290-302. CrossRef Medline

Chevaleyre V, Castillo PE (2003) Heterosynaptic LTD of hippocampal GABAergic synapses: a novel role of endocannabinoids in regulating excitability. Neuron 38:461-472. CrossRef Medline

Chevaleyre V, Siegelbaum SA (2010) Strong CA2 pyramidal neuron synapses define a powerful disynaptic cortico-hippocampal loop. Neuron 66:560-572. CrossRef Medline

Chevaleyre V, Heifets BD, Kaeser PS, Südhof TC, Purpura DP, Castillo PE (2007) Endocannabinoid-mediated long-term plasticity requires cAMP/ PKA signaling and RIM1alpha. Neuron 54:801-812. CrossRef Medline

Cohen GA, Doze VA, Madison DV (1992) Opioid inhibition of GABA release from presynaptic terminals of rat hippocampal interneurons. Neuron 9:325-335. CrossRef Medline

Commons KG, Milner TA (1996) Cellular and subcellular localization of delta opioid receptor immunoreactivity in the rat dentate gyrus. Brain Res 738:181-195. CrossRef Medline

Commons KG, Milner TA (1997) Localization of delta opioid receptor immunoreactivity in interneurons and pyramidal cells in the rat hippocampus. J Comp Neurol 381:373-387. CrossRef Medline

Crain BJ, Chang KJ, McNamara JO (1986) Quantitative autoradiographic analysis of mu and delta opioid binding sites in the rat hippocampal formation. J Comp Neurol 246:170-180. CrossRef Medline

Duka T, Wüster M, Schubert P, Stoiber R, Herz A (1981) Selective localization of different types of opiate receptors in hippocampus as revealed by in vitro autoradiography. Brain Res 205:181-186. CrossRef Medline

Dunwiddie TV, Su MT (1988) Pertussis toxin pretreatment antagonizes the actions of mu- and delta-opiate agonists in hippocampal slices. Neurosci Lett 95:329-334. CrossRef Medline

Erbs E, Faget L, Scherrer G, Kessler P, Hentsch D, Vonesch JL, Matifas A, Kieffer BL, Massotte D (2012) Distribution of delta opioid receptorexpressing neurons in the mouse hippocampus. Neuroscience 221:203213. CrossRef Medline

Faget L, Erbs E, Le Merrer J, Scherrer G, Matifas A, Benturquia N, Noble F, Decossas M, Koch M, Kessler P, Vonesch JL, Schwab Y, Kieffer BL, Massotte D (2012) In vivo visualization of delta opioid receptors upon phys- iological activation uncovers a distinct internalization profile. J Neurosci 32:7301-7310. CrossRef Medline

Filliol D, Ghozland S, Chluba J, Martin M, Matthes HW, Simonin F, Befort K, Gavériaux-Ruff C, Dierich A, LeMeur M, Valverde O, Maldonado R, Kieffer BL (2000) Mice deficient for delta- and mu-opioid receptors exhibit opposing alterations of emotional responses. Nat Genet 25:195-200. CrossRef Medline

Fuentealba P, Tomioka R, Dalezios Y, Márton LF, Studer M, Rockland K, Klausberger T, Somogyi P (2008) Rhythmically active enkephalinexpressing GABAergic cells in the $\mathrm{CA} 1$ area of the hippocampus project to the subiculum and preferentially innervate interneurons. J Neurosci 28 : 10017-10022. CrossRef Medline

Glickfeld LL, Atallah BV, Scanziani M (2008) Complementary modulation of somatic inhibition by opioids and cannabinoids. J Neurosci 28:1824-1832. CrossRef Medline

Hippenmeyer S, Vrieseling E, Sigrist M, Portmann T, Laengle C, Ladle DR, Arber S (2005) A developmental switch in the response of DRG neurons to ETS transcription factor signaling. Plos Biol 3:e159. CrossRef Medline

Iremonger KJ, Kuzmiski JB, Baimoukhametova DV, Bains JS (2011) Dual regulation of anterograde and retrograde transmission by endocannabinoids. J Neurosci 31:12011-12020. CrossRef Medline

Jin W, Chavkin C (1999) Mu opioids enhance mossy fiber synaptic transmission indirectly by reducing GABAB receptor activation. Brain Res 821:286-293. CrossRef Medline

Jones MW, McHugh TJ (2011) Updating hippocampal representations: CA2 joins the circuit. Trends Neurosci 34:526-535. CrossRef Medline

Jutkiewicz EM, Eller EB, Folk JE, Rice KC, Traynor JR, Woods JH (2004) Delta-opioid agonists: differential efficacy and potency of SNC80, its 3-OH (SNC86) and 3-desoxy (SNC162) derivatives in Sprague-Dawley rats. J Pharmacol Exp Ther 309:173-181. CrossRef Medline

Jutkiewicz EM, Rice KC, Traynor JR, Woods JH (2005) Separation of the convulsions and antidepressant-like effects produced by the delta-opioid agonist SNC80 in rats. Psychopharmacology (Berl) 182:588-596. CrossRef Medline

Knowles WD, Traub RD, Strowbridge BW (1987) The initiation and spread of epileptiform bursts in the in vitro hippocampal slice. Neuroscience 21:441-455. CrossRef Medline

Lee SE, Simons SB, Heldt SA, Zhao M, Schroeder JP, Vellano CP, Cowan DP, Ramineni S, Yates CK, Feng Y, Smith Y, Sweatt JD, Weinshenker D, Ressler KJ, Dudek SM, Hepler JR (2010) RGS14 is a natural suppressor of both synaptic plasticity in CA2 neurons and hippocampal-based learning and memory. Proc Natl Acad Sci U S A 107:16994-16998. CrossRef Medline

Le Merrer J, Rezaï X, Scherrer G, Becker JA, Kieffer BL (2013) Impaired hippocampus-dependent and facilitated striatum-dependent behaviors in mice lacking the delta opioid receptor. Neuropsychopharmacology 38:1050-1059. CrossRef Medline

Margolis EB, Mitchell JM, Hjelmstad GO, Fields HL (2011) A novel opioid receptor-mediated enhancement of GABAA receptor function induced by stress in ventral tegmental area neurons. J Physiol 589:4229-4242. CrossRef Medline

Mercer A, Trigg HL, Thomson AM (2007) Characterization of neurons in the CA2 subfield of the adult rat hippocampus. J Neurosci 27:7329-7338. CrossRef Medline

Mercer A, Eastlake K, Trigg HL, Thomson AM (2012) Local circuitry involving parvalbumin-positive basket cells in the CA2 region of the hippocampus. Hippocampus 22:43-56. CrossRef Medline

Nakashiba T, Young JZ, McHugh TJ, Buhl DL, Tonegawa S (2008) Transgenic inhibition of synaptic transmission reveals role of CA3 output in hippocampal learning. Science 319:1260-1264. CrossRef Medline

Nicoll RA, Alger BE, Jahr CE (1980) Enkephalin blocks inhibitory pathways in the vertebrate CNS. Nature 287:22-25. CrossRef Medline

Ormond J, Woodin MA (2009) Disinhibition mediates a form of hippocampal long-term potentiation in area CA1. PLoS One 4:e7224. CrossRef Medline

Piskorowski RA, Chevaleyre V (2012) Synaptic integration by different dendritic compartments of hippocampal CA1 and CA2 pyramidal neurons. Cell Mol Life Sci 69:75-88. CrossRef Medline

Piskorowski R, Santoro B, Siegelbaum SA (2011) TRIP8b splice forms act in concert to regulate the localization and expression of HCN1 channels in CA1 pyramidal neurons. Neuron 70:495-509. CrossRef Medline

Quock RM, Burkey TH, Varga E, Hosohata Y, Hosohata K, Cowell SM, Slate 
CA, Ehlert FJ, Roeske WR, Yamamura HI (1999) The delta-opioid receptor: molecular pharmacology, signal transduction, and the determination of drug efficacy. Pharmacol Rev 51:503-532. Medline

Rezaï X, Faget L, Bednarek E, Schwab Y, Kieffer BL, Massotte D (2012) Mouse delta opioid receptors are located on presynaptic afferents to hippocampal pyramidal cells. Cell Mol Neurobiol 32:509-516. CrossRef Medline

Ribak CE, Seress L, Leranth C (1993) Electron microscopic immunocytochemical study of the distribution of parvalbumin-containing neurons and axon terminals in the primate dentate gyrus and Ammon's horn. J Comp Neurol 327:298-321. CrossRef Medline

Sar M, Stumpf WE, Miller RJ, Chang KJ, Cuatrecasas P (1978) Immunohistochemical localization of enkephalin in rat brain and spinal cord. J Comp Neurol 182:17-37. CrossRef Medline

Scherrer G, Tryoen-Tóth P, Filliol D, Matifas A, Laustriat D, Cao YQ, Basbaum AI, Dierich A, Vonesh JL, Gavériaux-Ruff C, Kieffer BL (2006) Knockin mice expressing fluorescent delta-opioid receptors uncover G-protein-coupled receptor dynamics in vivo. Proc Natl Acad Sci U S A 103:9691-9696. CrossRef Medline

Simmons ML, Chavkin C (1996) Endogenous opioid regulation of hippocampal function. Int Rev Neurobiol 39:145-196. CrossRef Medline

Simons SB, Escobedo Y, Yasuda R, Dudek SM (2009) Regional differences in hippocampal calcium handling provide a cellular mechanism for limiting plasticity. Proc Natl Acad Sci U S A 106:14080-14084. CrossRef Medline

Sohal VS, Zhang F, Yizhar O, Deisseroth K (2009) Parvalbumin neurons and gamma rhythms enhance cortical circuit performance. Nature 459: 698-702. CrossRef Medline

Stumm RK, Zhou C, Schulz S, Höllt V (2004) Neuronal types expressing $\mathrm{mu}$ - and delta-opioid receptor mRNA in the rat hippocampal formation. J Comp Neurol 469:107-118. CrossRef Medline

Svoboda KR, Adams CE, Lupica CR (1999) Opioid receptor subtype expression defines morphologically distinct classes of hippocampal interneurons. J Neurosci 19:85-95. Medline
Tsetsenis T, Younts TJ, Chiu CQ, Kaeser PS, Castillo PE, Südhof TC (2011) Rab3B protein is required for long-term depression of hippocampal inhibitory synapses and for normal reversal learning. Proc Natl Acad Sci U S A 108:14300-14305. CrossRef Medline

van den Pol AN (2012) Neuropeptide transmission in brain circuits. Neuron 76:98-115. CrossRef Medline

Wagner JJ, Etemad LR, Thompson AM (2001) Opioid-mediated facilitation of long-term depression in rat hippocampus. J Pharmacol Exp Ther 296: 776-781. Medline

Wigström H, Gustafsson B (1985) Facilitation of hippocampal long-lasting potentiation by GABA antagonists. Acta Physiol Scand 125:159-172. CrossRef Medline

Williamson A, Spencer DD (1994) Electrophysiological characterization of CA2 pyramidal cells from epileptic humans. Hippocampus 4:226-237. CrossRef Medline

Wittner L, Huberfeld G, Clémenceau S, Eross L, Dezamis E, Entz L, Ulbert I, Baulac M, Freund T, Maglóczky Z, Miles R (2009) The epileptic human hippocampal cornu ammonis 2 region generates spontaneous interictallike activity in vitro. Brain 132:3032-3046. CrossRef Medline

Xie CW, Lewis DV (1995) Depression of LTP in rat dentate gyrus by naloxone is reversed by GABAA blockade. Brain Res 688:56-60. CrossRef Medline

Zhang ZJ, Reynolds GP (2002) A selective decrease in the relative density of parvalbumin-immunoreactive neurons in the hippocampus in schizophrenia. Schizophr Res 55:1-10. CrossRef Medline

Zhao M, Choi YS, Obrietan K, Dudek SM (2007) Synaptic plasticity (and the lack thereof) in hippocampal CA2 neurons. J Neurosci 27: 12025-12032. CrossRef Medline

Zhou HY, Chen SR, Chen H, Pan HL (2010) Opioid-induced long-term potentiation in the spinal cord is a presynaptic event. J Neurosci 30:44604466. CrossRef Medline

Zieglgänsberger W, French ED, Siggins GR, Bloom FE (1979) Opioid peptides may excite hippocampal pyramidal neurons by inhibiting adjacent inhibitory interneurons. Science 205:415-417. CrossRef Medline 